\title{
Quantifying the mass loading of particles in an ash cloud remobilized from tephra deposits on Iceland
}

\author{
Frances Beckett ${ }^{1}$, Arve Kylling ${ }^{2}$, Guðmunda Sigurðardóttir ${ }^{3}$, Sibylle von Löwis ${ }^{3}$, and Claire Witham ${ }^{1}$ \\ ${ }^{1}$ Met Office, Exeter, UK \\ ${ }^{2}$ NILU-Norwegian Institute for Air Research, Oslo, Norway \\ ${ }^{3}$ Icelandic Meteorological Office, Reykjavik, Iceland
}

Correspondence to: Frances Beckett (frances.beckett@metoffice.gov.uk)

Received: 29 July 2016 - Discussion started: 17 August 2016

Revised: 25 January 2017 - Accepted: 7 March 2017 - Published: 3 April 2017

\begin{abstract}
On 16-17 September 2013 strong surface winds over tephra deposits in southern Iceland led to the resuspension and subsequent advection of significant quantities of volcanic ash. The resulting resuspended ash cloud was transported to the south-east over the North Atlantic Ocean and, due to clear skies at the time, was exceptionally well observed in satellite imagery. We use satellite-based measurements in combination with radiative transfer and dispersion modelling to quantify the total mass of ash resuspended during this event. Typically ash clouds from explosive eruptions are identified in satellite measurements from a negative brightness temperature difference (BTD) signal; however this technique assumes that the ash resides at high levels in the atmosphere. Due to a temperature inversion in the troposphere over southern Iceland during 16 September 2013, the resuspended ash cloud was constrained to altitudes of $<2 \mathrm{~km}$ a.s.l. We show that a positive BTD signal can instead be used to identify ash-containing pixels from satellite measurements. The timing and location of the ash cloud identified using this technique from measurements made by the Visible Infrared Imaging Radiometer Suite (VIIRS) on board the Suomi National Polar-orbiting Partnership (NPP) satellite agree well with model predictions using the dispersion model NAME (Numerical Atmospheric-dispersion Modelling Environment). Total column mass loadings are determined from the VIIRS data using an optimal estimation technique which accounts for the low altitude of the resuspended ash cloud and are used to calibrate the emission rate in the resuspended ash scheme in NAME. Considering the tephra deposits from the recent eruptions of Eyjafjallajökull and Grímsvötn as the potential source area for resuspension for this event, we es-
\end{abstract}

timate that $\sim 0.2 \mathrm{Tg}$ of ash was remobilized during 16-17 September 2013.

\section{Introduction}

Iceland is one of the most active volcanic regions on Earth, with $\geq 20$ eruptions per century (Thordarson and Höskuldsson, 2008), and explosive eruptions can leave behind widespread ash deposits (e.g. Larsen et al., 2001; Carey et al., 2010; Jude-Eton et al., 2012). These deposits are subject to intense aeolian processes: Iceland is windy, and the lack of vegetation inhibits soil formation and particle binding, resulting in significant remobilization events in the years following a volcanic eruption (Arnalds et al., 2016). The eruptions of Eyjafjallajökull in 2010 and Grímsvötn in 2011 provided a fresh source of unconsolidated ash deposits in southern Iceland, and there have been a number of significant resuspended ash events in the years following these eruptions (Thorsteinsson et al., 2012; Arnalds et al., 2013). Between 19 September 2010 and 16 February 2011 there were 12 observed resuspension episodes recorded by $\mathrm{PM}_{10}$ counters in Drangshlidardalur (southern Iceland) of the Eyjafjallajökull ash deposits (Leadbetter et al., 2012). Following a blizzard on 6 March 2013 resuspended ash was deposited in Reykjavik, and particles were identified as having originated from both the Eyjafjallajökull 2010 and Grímsvötn 2011 deposits (Liu et al., 2014). Resuspended "ash storms" can pose a significant hazard to the local population; decreased visibility levels impact ground transportation and airports (Guffanti et al., 2009; Liu et al., 2014) and poor-air-quality episodes 
(a) VIIRS 16/09/2013 13:36 UTC

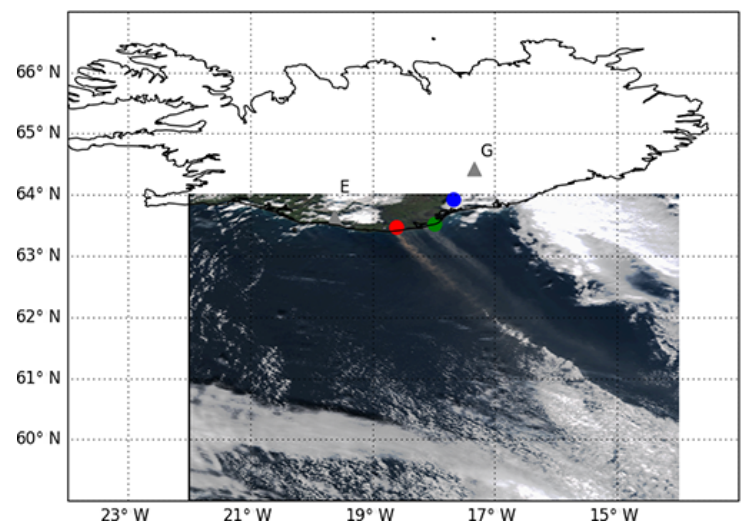

(b)

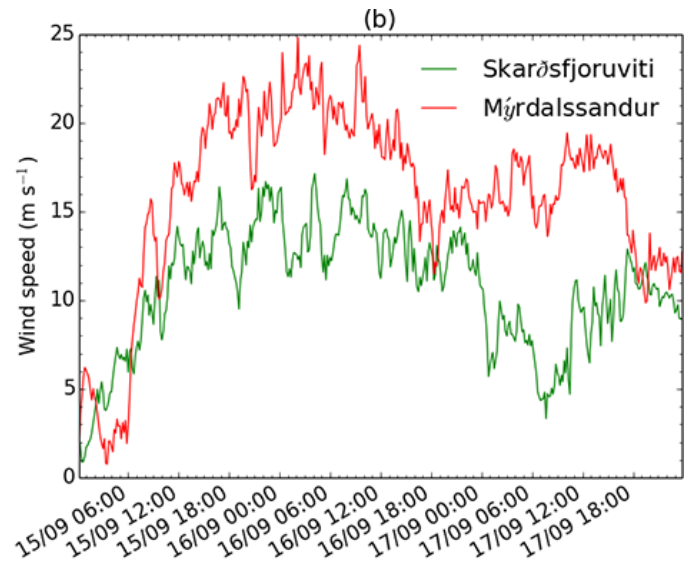

Figure 1. (a) "True"-colour VIIRS daytime image for 13:35 UTC on 16 September 2013 with the locations of the Skarðsfjöruviti (green marker) and Mýrdalssandur (red marker) weather stations. The location of the OPC at Maríubakki is indicated by the blue marker. The locations of the volcanoes Eyjafjallajökull and Grímsvötn are indicated on the map by the E and G symbols respectively. (b) The recorded wind speeds at Skarðsfjöruviti and Mýrdalssandur during 15-17 September 2013.

can be a concern for human health (e.g. Horwell and Baxter, 2006) and livestock (Wilson et al., 2011).

Following the eruption of Eyjafjallajökull in 2010, which deposited $140 \pm 20 \times 10^{6} \mathrm{~m}^{3}$ of tephra in Iceland (Gudmundsson et al., 2012), the Met Office in the UK has provided routine forecasts to the Icelandic Meteorological Office (IMO) which indicate the likely timing and location of resuspended ash clouds. Forecasts are produced using the Lagrangian atmospheric dispersion model NAME (Numerical Atmospheric-dispersion Modelling Environment; Jones et al., 2007), which includes a resuspension scheme developed by Leadbetter et al. (2012). Resuspended particles are advected by three-dimensional winds provided by the Met Office's Numerical Weather Prediction (NWP) model and dispersed using random-walk techniques which account for turbulent structures in the atmosphere (Maryon et al., 1999; Thomson and Wilson, 2013). Particles are removed from the atmosphere by both dry- and wet-deposition processes (Webster and Thomson, 2011, 2014).

The emission of remobilized particles depends on the meteorological conditions; soil moisture; terrain roughness; and characteristics of the fallout deposit, including the size and density of particles and deposit thickness (Gillette and Passi, 1988). NAME includes a dust scheme which explicitly models the resuspension of mineral particles; the emission rate and the size distribution of the resuspended particles are calculated as a function of soil moisture, vegetation fraction, clay fraction, and the wind friction velocity (Woodward, 2001; Athanassiadou et al., 2006). However, information on the spatially varying surface characteristics of ash deposits is often not available, especially when the deposits are relatively recent (Leadbetter et al., 2012; Folch et al., 2014). Instead Leadbetter et al. (2012) implemented a simple emission scheme in NAME for resuspended volcanic ash in which re- mobilization occurs when the local wind friction velocity exceeds a prescribed threshold and precipitation rates are low. Emission rates were calibrated using measured $\mathrm{PM}_{10}$ data collected at multiple sites across Iceland from two significant resuspension events during 23 May-2 July 2010 and 21 September 2010-16 February 2011, shortly after the eruption of Eyjafjallajökull in 2010. However, in the following year the eruption of Grímsvötn resulted in further widespread tephra deposits (Hreinsdöttir et al., 2014), providing an additional source of remobilized ash which is not accounted for in the calibration presented in Leadbetter et al. (2012). It is also expected that the scaling coefficient used to calculate emission rates of resuspended ash in the Leadbetter et al. (2012) approach will vary with time as deposits are dispersed, eroded, and compacted.

During 16-17 September 2013 strong surface winds over tephra deposits in southern Iceland led to the resuspension and subsequent advection of significant quantities of volcanic ash particles. The resuspended ash cloud was transported to the south-east over the North Atlantic Ocean and, due to clear skies at the time, was exceptionally well observed in satellite imagery. Here we use satellite-based measurements in combination with radiative transfer modelling to quantify the total column mass loadings of the resuspended ash cloud. These are then used to calibrate the emission rate applied in the resuspension scheme in NAME. The newly calibrated scheme can be used to provide more accurate quantitative forecasts of future events and to assess how resuspension rates vary over time.

Dust and volcanic ash may be detected by satellite instruments sensitive to either solar or thermal radiation. Infrared (IR) detection of ash clouds and retrieval of ash cloud properties have been described by, for example, Prata (1989), Wen and Rose (1994), Francis et al. (2012), and 
Prata and Prata (2012). Gu et al. (2003) used IR bands 31 and 32 of the Moderate Resolution Imaging Spectroradiometer (MODIS) to detect and quantify a sandstorm in China, and the solar channels of MODIS are routinely used to produce aerosol charts (Remer et al., 2005). We analyse data from the Visible Infrared Imaging Radiometer Suite (VIIRS) on board the Suomi National Polar-orbiting Partnership (Suomi NPP) satellite. The brightness temperature difference (BTD) between VIIRS bands M15 and M16, BTDV = $\mathrm{BT}_{\mathrm{M} 15}-\mathrm{BT}_{\mathrm{M} 16}$, can be used to detect volcanic ash using an approach similar to that applied to MODIS bands 31 and 32 (Watson et al., 2004; Novak et al., 2008; Corradini et al., 2008). The $\mathrm{BTD}_{V}$ signal depends on a number of factors including the properties of the ash particles (their size and shape), the altitude of the ash cloud, and the temperature of the Earth's surface (Prata and Grant, 2001). Dispersed ash following the eruption of a volcano often resides at high altitudes in the atmosphere, giving a negative $\mathrm{BTD}_{\mathrm{V}}$ signal, compared to ice clouds, which give positive $\mathrm{BTD}_{\mathrm{V}}$ values. In this study we explore how to identify low-altitude resuspended ash clouds using the split-window method.

The manuscript is organized as follows. In Sect. 2 observations from the event are presented: meteorological, particulate air concentrations from an optical particle counter (OPC), and satellite imagery. In Sect. 3 the radiative transfer and dispersion modelling is described. In Sect. 4 we calibrate the emission rate in the resuspension scheme in NAME with the satellite-retrieved total column mass loadings and quantify the total mass of ash resuspended during 16-17 September 2013. We discuss the results in Sect. 5, before the conclusions are presented in Sect. 6.

\section{Observations}

\subsection{Meteorology}

During 16-17 September 2013 strong winds prevailed over southern Iceland. Surface wind speeds of up to $25 \mathrm{~m} \mathrm{~s}^{-1}$ were recorded at weather stations located at Skarðsfjöruviti and Mýrdalssandur, close to the ash deposits from the eruptions of Eyjafjallajökull in 2010 and Grímsvötn in 2011 (Fig. 1). Wind direction data retrieved from radiosonde ascents at 12:00 UTC at Keflavík Airport indicate that on 16 September near-surface winds were north-westerly, veering northeasterly by 17 September (Fig. 2). Temperature profiles from the ascents show that there was a temperature inversion at $850 \mathrm{hPa}(\sim 1500 \mathrm{~m}$ a.s.l.) on 16 September. This is also observed in the profile from 17 September, although it is now weaker.

\subsection{Optical particle counters}

Increased $\mathrm{PM}_{10}$ concentrations were recorded by an OPC located at Maríubakki during 16-17 September 2013. The flow rate sampled by the OPC is $1 \mathrm{~L} \mathrm{~min}^{-1}$, and particle concen-

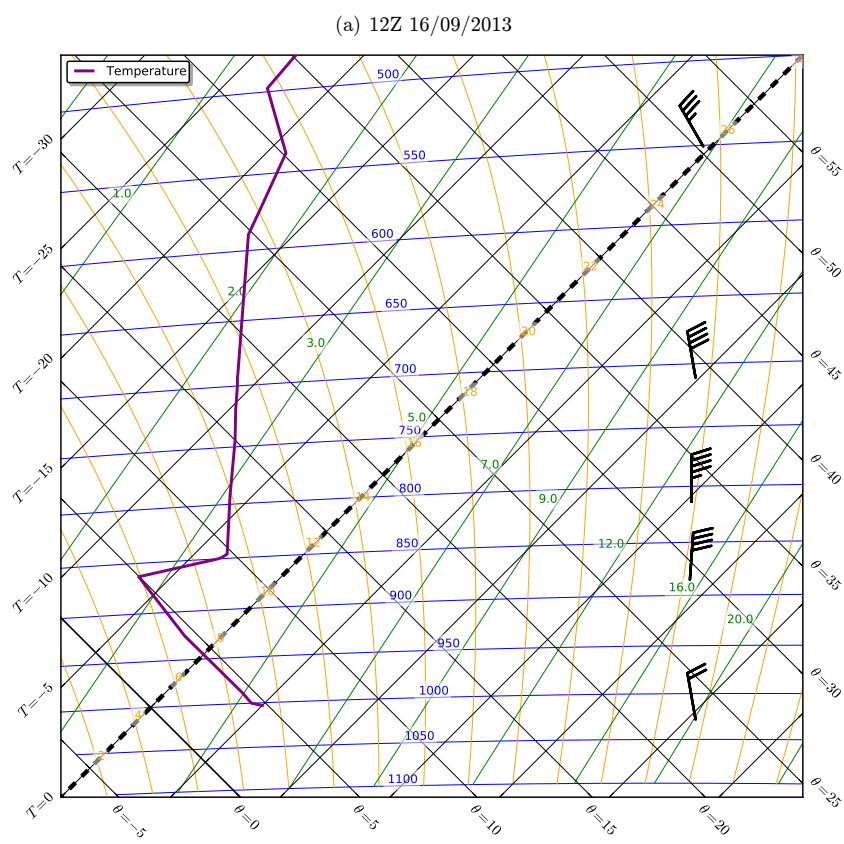

(b) $12 \mathrm{Z} 17 / 09 / 2013$

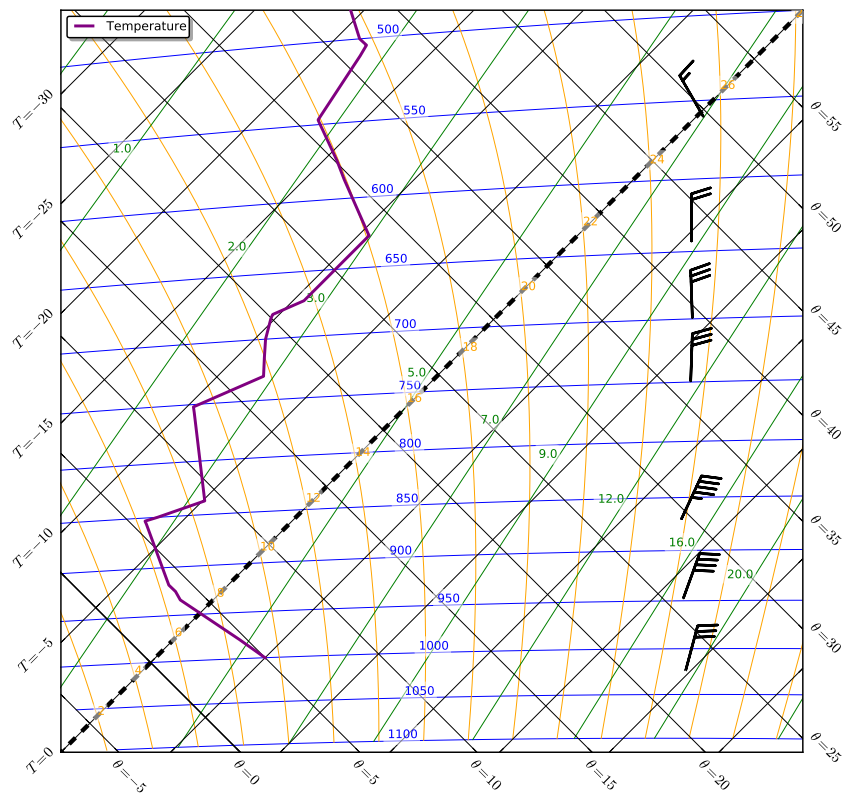

Figure 2. Radiosonde data retrieved from launches at Keflavík Airport at 12:00 UTC on (a) 16 and (b) 17 September 2013. Northwesterly surface winds prevail on 16 September, and a temperature inversion is observed at $850 \mathrm{hPa}, \sim 1500 \mathrm{~m}$ a.s.l. (where pressure is indicated by the blue lines). On 17 September surface winds have veered north-easterly; the temperature inversion remains although it is now weaker. Radiosonde data were obtained from http://weather.uwyo.edu/upperair/sounding.html.

trations are calculated from the count data by assuming that particles are spherical and have a density of $2300 \mathrm{~kg} \mathrm{~m}^{-3}$. Figure 3 shows the time series of calculated particle concentrations. The peak concentration of $1.44 \times 10^{-4} \mathrm{~g} \mathrm{~m}^{-3}$ 
Table 1. VIIRS bands used in this study. Further information is available from https://www.star.nesdis.noaa.gov/smcd/spb/nsun/ snpp/VIIRS/VIIRS_SDR_Users_guide.pdf.

\begin{tabular}{lrl}
\hline $\begin{array}{l}\text { Band } \\
\text { no. }\end{array}$ & $\begin{array}{r}\text { Central wavelength } \\
(\mu \mathrm{m})\end{array}$ & Usage \\
\hline M3 & 0.488 & RGB composite \\
M4 & 0.555 & RGB composite \\
M5 & 0.672 & RGB composite \\
M15 & 10.763 & Ash detection and retrieval \\
M16 & 12.013 & Ash detection and retrieval \\
\hline
\end{tabular}

occurs at 09:00 UTC on 17 September 2013. The observed air concentrations are lower than those recorded by $\mathrm{PM}_{10}$ monitors during resuspension episodes in 2010 following the eruption of Eyjafjallajökull, which typically ranged between $10^{-4}$ and $10^{-3} \mathrm{~g} \mathrm{~m}^{-3}$ (Leadbetter et al., 2012). The lower mass loadings recorded during this event perhaps reflect the availability of data from only one OPC, which was not positioned under the main axis of the resuspended ash cloud but instead was located at the edge of the plume as indicated in Fig. 1a.

\subsection{Satellite imagery}

The Suomi NPP satellite including VIIRS (http://npp.gsfc. nasa.gov/viirs.html) was launched on 28 October 2011 and placed in a sun-synchronous orbit at an altitude of $\sim 842 \mathrm{~km}$. VIIRS has 22 bands in the solar and thermal parts of the spectrum, and the bands used in this study are listed in Table 1. The spatial resolution of VIIRS is band-dependent: the M3-M5 bands have a spatial resolution of $0.742 \mathrm{~km} \times 0.259 \mathrm{~km}$ (down-track $\times$ cross-track) at nadir $(1.60 \mathrm{~km} \times 1.58 \mathrm{~km}$ at end of scan), whilst the M15 and M16 bands have a spatial resolution of $0.742 \mathrm{~km} \times 0.776 \mathrm{~km}$ at nadir $(1.60 \mathrm{~km} \times 1.58 \mathrm{~km}$ at end of scan). The M15 and M16 infrared bands have prelaunch measured noise equivalent delta temperatures (NE $\Delta T$ ) of 0.028 and $0.036 \mathrm{~K}$ respectively.

From the visible channels (M3, M4, and M5) "true"-colour images can be produced during the daytime. In order to have data during the night-time as well, the infrared bands (M15 and M16) are used. The brightness temperature (BT) in the M15 and M16 bands varies with the amount of water vapour in the atmosphere, the atmospheric temperature profile, and the temperature of the underlying surface. For these parameters analysis data from the European Centre for Medium-Range Weather Forecasts (ECMWF) were utilized (Supplement Figs. S1-S4) to estimate water vapour effects (Sect. 3.2).

There are approximately six VIIRS overpasses over Iceland every day, typically three during the daytime and three at night. A list of all the night and daytime overpasses used in this study is given in Table 2. Note that the overpass at
01:47 UTC on 17 September 2013 is not included in the analysis as it contained no clear ash signal and the study area was on the edge of the swath. Figure 4 shows the RGB (redgreen-blue) composites from the daytime overpasses during 16-17 September 2013; the resuspended ash cloud is clearly observed and shown to be dispersing over the North Atlantic to the south-east. The M15 brightness temperatures for the day and night-time overpasses are shown in Fig. S5.

\section{Modelling}

\subsection{Dispersion model forecasts}

The atmospheric dispersion model NAME includes a scheme to model the resuspension of volcanic ash (Leadbetter et al., 2012). Particles are remobilized from the surface when the local friction velocity $\left(U^{*}\right)$, which characterizes the wind shear at the surface, exceeds a threshold friction velocity $\left(U_{\mathrm{t}}^{*}\right)$. The threshold friction velocity depends on the properties of the particles (their size and density) and on the surface conditions - such as soil moisture and roughness, and vegetation cover. Information on the spatially varying characteristics of volcanic ash deposits is often unavailable, particularly as deposits change with time due to erosion, compaction and remobilization. Leadbetter et al. (2012) found that using a threshold friction velocity of $0.4 \mathrm{~m} \mathrm{~s}^{-1}$ was most appropriate for modelling the resuspension of ash from deposits following the 2010 eruption of Eyjafjallajökull in Iceland. They also note that this agrees well with a threshold of $0.42 \mathrm{~m} \mathrm{~s}^{-1}$ identified from wind tunnel experiments (Sigurjonsson et al., 1999). Folch et al. (2014) also found that a threshold friction velocity of $0.4 \mathrm{~m} \mathrm{~s}^{-1}$ was most appropriate when modelling the resuspension of fallout deposits from the June 2011 Cordón Caulle eruption in central Patagonia during October 2011. We take the threshold friction velocity to be $0.4 \mathrm{~m} \mathrm{~s}^{-1}$ and assume that resuspension does not occur when precipitation rates are $>0.01 \mathrm{~mm} \mathrm{~h}^{-1}$. The meteorological fields used in this study are provided by the NAE (North Atlantic and European) configuration of the Met Office's Unified Model (UM; Davies et al., 2005), which has a horizontal resolution of $12 \mathrm{~km}$ (Bush et al., 2006).

We consider the deposits from the eruptions of Eyjafjallajökull in 2010 and Grímsvötn in 2011 to be potential sources of resuspended ash. The extent of the Eyjafjallajökull 2010 ash is based on a deposit map provided by Gudmundsson et al. (2012). In the absence of a published map of Grímsvötn deposits we use a modelled deposit generated using NAME to simulate the eruption of Grímsvötn in 2011, as described by Liu et al. (2014). All regions where ash has a depth $>5 \mathrm{~mm}$ are considered, and the source areas used are indicated in Fig. 5. Source regions are represented in NAME by a horizontal grid with a resolution of $0.01^{\circ}$ longitude and $0.01^{\circ}$ latitude. The driving meteorology is considered at each grid 


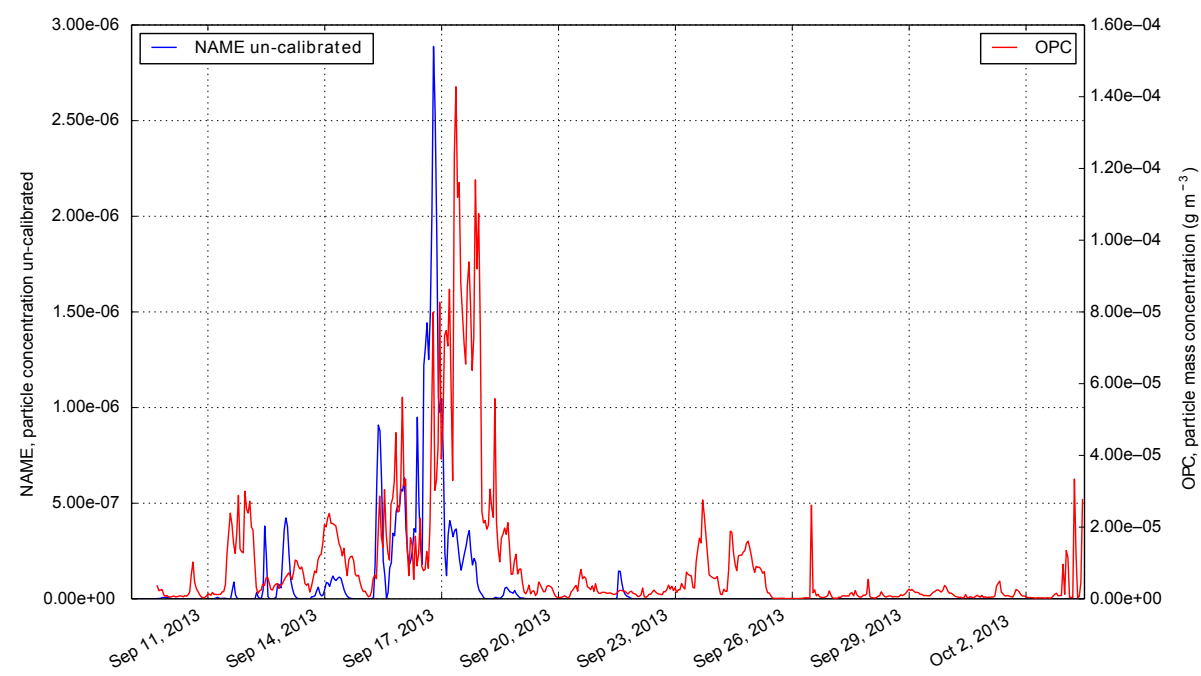

Figure 3. Time series of $1 \mathrm{~h}$ averaged concentrations of resuspended ash derived from OPC count data (red) compared to the un-calibrated modelled air concentrations (blue) at Maríubakki during September 2013.
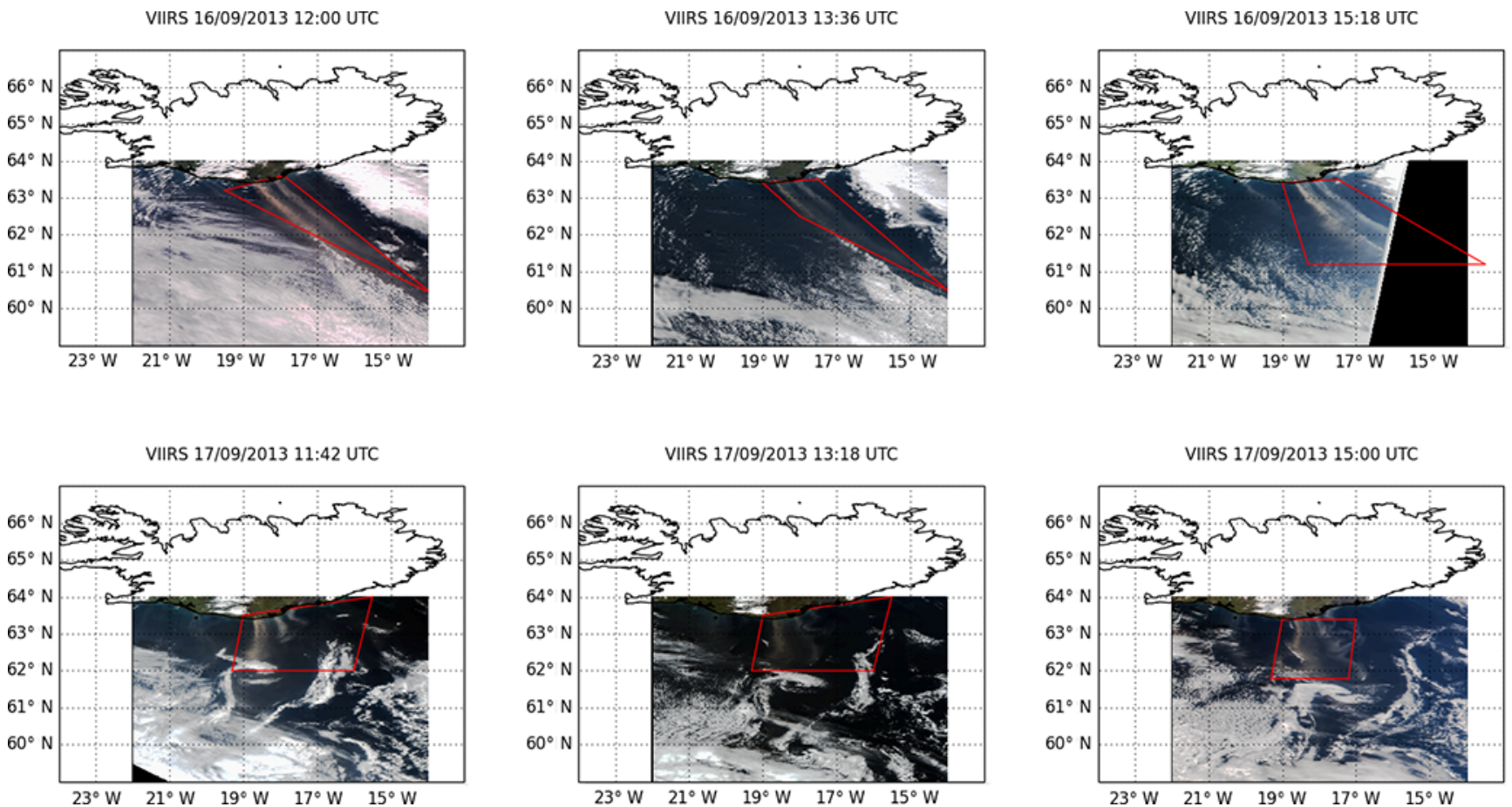

Figure 4. VIIRS daytime RGB composites using bands M3, M4, and M5 for 16-17 September 2013. Areas identified as containing resuspended ash (see Sect. 3.3) are enclosed within the red polygons.

cell in order to determine whether particles should be resuspended.

Where resuspension occurs, model particles are released with a uniform distribution between 0 and $10 \mathrm{~m}$ above the ground and are assigned a density of $2300 \mathrm{~kg} \mathrm{~m}^{-3}$. Their size distribution depends on the source: the particle size distribution (PSD) of the Eyjafjallajökull 2010 ash is based on measurements of samples collected from deposits on 15 April
2010 (Gislason et al., 2011), whilst the PSD of the Grímsvötn ash is based on samples collected from deposits on 22 May 2011 (Olsson et al., 2013). To be able to compare the modelled ash cloud to the OPC measurements and the satellite retrievals, we only model particles with diameters between 1 and $10 \mu \mathrm{m}$ (Kylling et al., 2014; Stevenson et al., 2015). The 

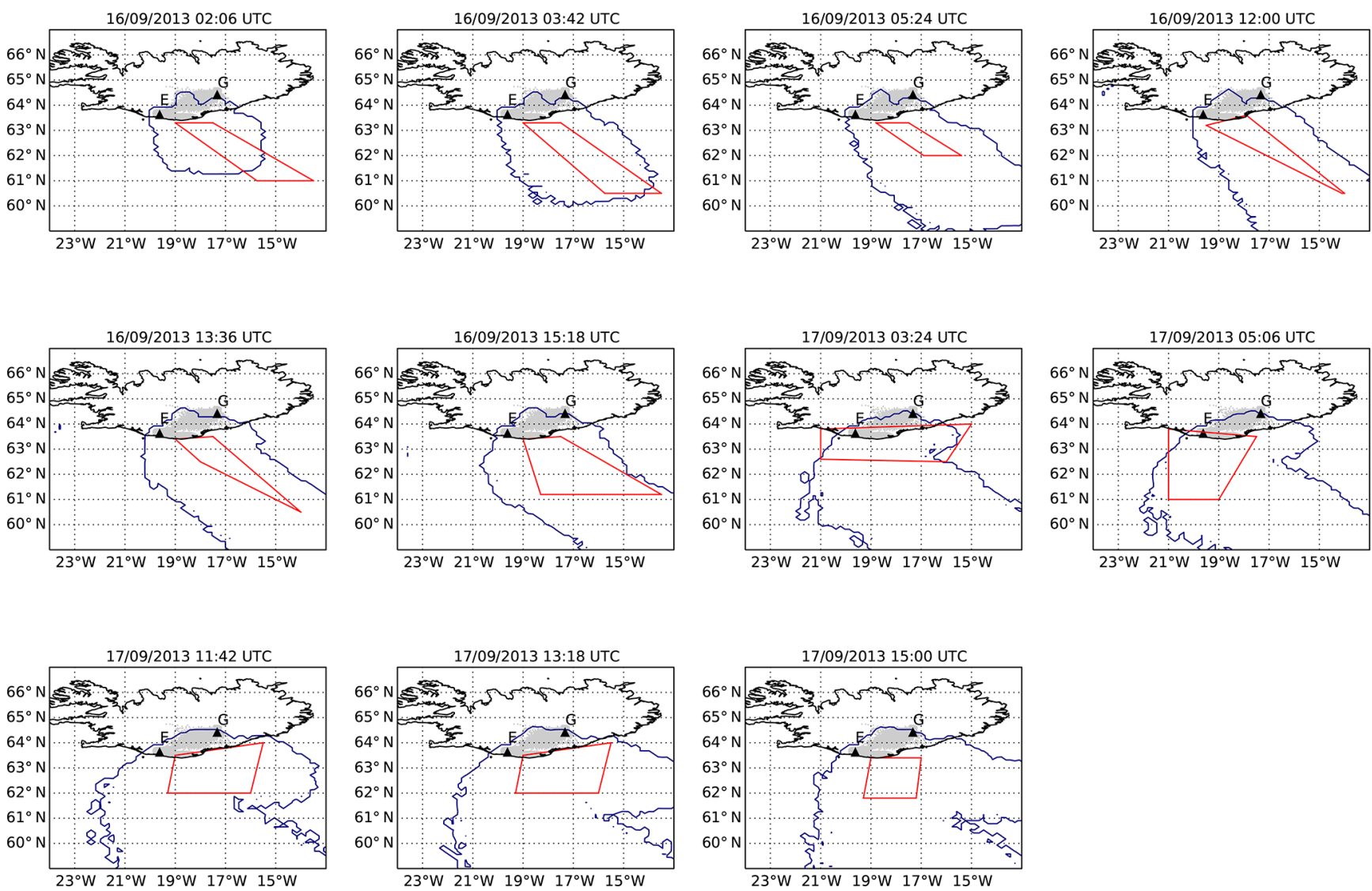

Figure 5. Comparison of the location of the modelled resuspended ash cloud, represented by the blue line, to the area identified from VIIRS retrieval data, represented by the red polygons; see Sect. 3.3 for the methodology used to define this area. The outline of the modelled plume is derived from un-calibrated $1 \mathrm{~h}$ averaged total column mass loadings; values $>10^{-7} \mathrm{~g} \mathrm{~m}^{-2}$ are considered. The source areas are identified by the grey areas.

rate at which particles are remobilized is proportional to the cube of the excess friction velocity:

$F=K\left(U^{*}-U_{\mathrm{t}}^{*}\right)^{3}$,

where $K$ is a dimensional constant used as a scaling coefficient. Without calibration $K$ is set to $1 \mathrm{~g} \mathrm{~s}^{-1}$, the emission rate increases as $U^{*}$ increases, and modelled air concentrations indicate areas of high and low concentrations, but the results are not quantitative. A discussion on the uncertainties associated with the model set-up, the source areas, precipitation thresholds, and source mixing by previous remobilization can be found in Liu et al. (2014).

Figure 3 shows the time series of calculated air concentrations from OPC count data at Maríubakki for the period 9 September to 2 October 2013. Modelled air concentrations using the un-calibrated emission rate $\left(K=1 \mathrm{~g} \mathrm{~s}^{-1}\right)$ are compared. The modelled peak concentration is at 19:00 UTC on 16 September 2013, $\sim 19 \mathrm{~h}$ earlier than the recorded peak concentration by the OPC at 09:00 UTC on 17 September 2013. A possible explanation for this time lag between the modelled and observed peaks could be that resuspension is suppressed in NAME when precipitation rates are $>0.01 \mathrm{~mm} \mathrm{~h}^{-1}$. This approach does not account for the time required to wet the deposit and prevent resuspension, and to dry the deposit before resuspension can restart. However, in comparing the particle concentrations from the OPC count data and the un-calibrated model output to the NAE precipitation rates and local friction velocity at Maríubakki, we show that there was no precipitation in Maríubakki during 15-17 September, indicating that during the $24 \mathrm{~h}$ prior to the modelled peak concentration the deposit was dry (Fig. 6a and $b$ ). Therefore it is unlikely that the offset in the modelled and observed peak concentrations can be ascribed to the lack of parameterization for a drying-out process in NAME. Figure $6 \mathrm{c}$ and $\mathrm{d}$ show that the peak in the OPC data does not correspond well with the peak in the modelled friction velocity $\left(U^{*}\right)$. This suggests that a significant fraction of the resuspended ash particles detected by the OPC at Maríubakki must have been transported into the area from surrounding deposits. Comparing dispersed model output with data collected at a single point location is challenging and non-ideal 

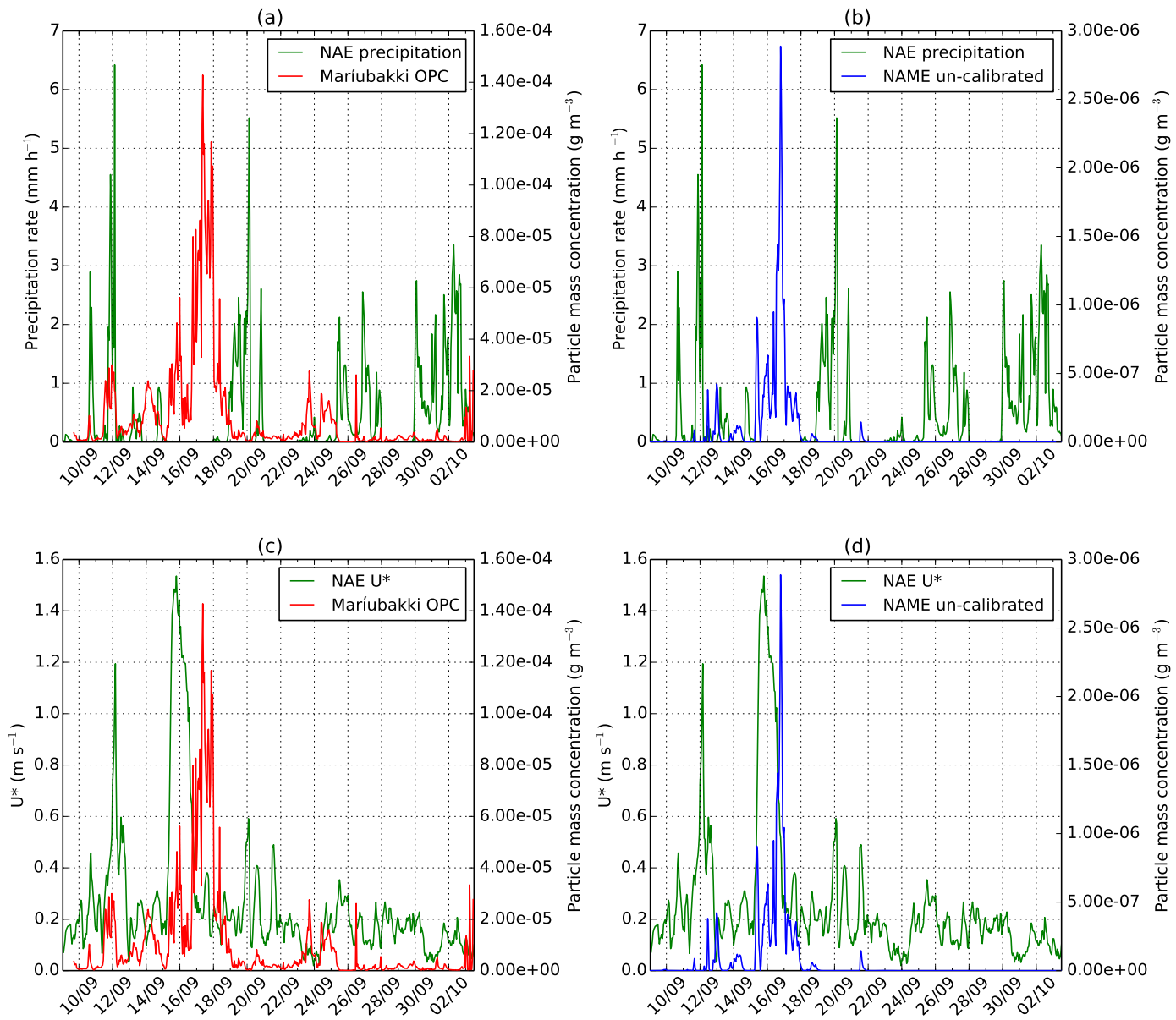

Figure 6. Time series of $1 \mathrm{~h}$ averaged air concentrations of resuspended ash derived from OPC count data and the un-calibrated model output, compared to the NAE precipitation rate and friction velocity $\left(U^{*}\right)$ at Maríubakki.

for a model calibration (e.g. Webster et al., 2012). Possible explanations for the offset in the observed and modelled peak air concentrations could be that the NWP model did not accurately represent the local topography, leading to errors in the modelled wind vectors, or uncertainty in the modelled precipitation. It could also be associated with uncertainty in the defined source areas or uncertainty associated with the OPC data.

The modelled location of the resuspended ash during 1617 September 2013 at the times corresponding to the VIIRS data is shown by the blue lines in Fig. 5. The edge of the ash cloud is identified as $1 \mathrm{~h}$ averaged mass loadings $>1 \times 10^{-7} \mathrm{~g} \mathrm{~m}^{-2}$, with this threshold taken as a pragmatic plotting choice as the emission rate is un-calibrated. Figure 5 shows that ash is resuspended from both the Eyjafjallajökull and Grímsvötn deposits and transported to the southeast over the North Atlantic on 16 September and then to the south-west as the wind changes direction on 17 September (Fig. 2). Both the location and timing of the modelled ash cloud agree well with the VIIRS daytime RGB composites (cf. Fig. 4). Figure 7 shows the maximum height of the modelled ash cloud and indicates that ash resided at low levels in the atmosphere, $<1600$ on 16 September and $<2000 \mathrm{~m}$ a.s.l. on 17 September. This suggests that the ash cloud was trapped below the temperature inversion, at $\sim 1500$ m (Fig. 2).

\subsection{Brightness temperature difference signal}

The brightness temperature difference between VIIRS bands $\mathrm{M} 15$ and $\mathrm{M} 16, \mathrm{BTDV}_{\mathrm{V}}=\mathrm{BT}_{\mathrm{M} 15}-\mathrm{BT}_{\mathrm{M} 16}$, can be used to detect volcanic ash. To determine the expected $\mathrm{BTD}_{\mathrm{V}}$ signal for the altitudes at which the resuspended ash cloud resided during 16-17 September 2013, radiative transfer calculations were carried out for a number of ash cloud top heights. Figure $8 \mathrm{a}$ shows calculated $\mathrm{BTDV}_{\mathrm{V}}$ for a $1 \mathrm{~km}$ thick ash cloud with varying ash mass loadings and ash cloud top heights ranging from 0.5 to $10.0 \mathrm{~km}$. For the ash cloud with a maximum altitude of $0.5 \mathrm{~km}$ the ash concentration was doubled to preserve constant mass. In addition, a simulation with all the ash in a $10 \mathrm{~cm}$ thick layer on the surface was included. The assumption of an ash layer with a thickness of $1.0 \mathrm{~km}$ is based 

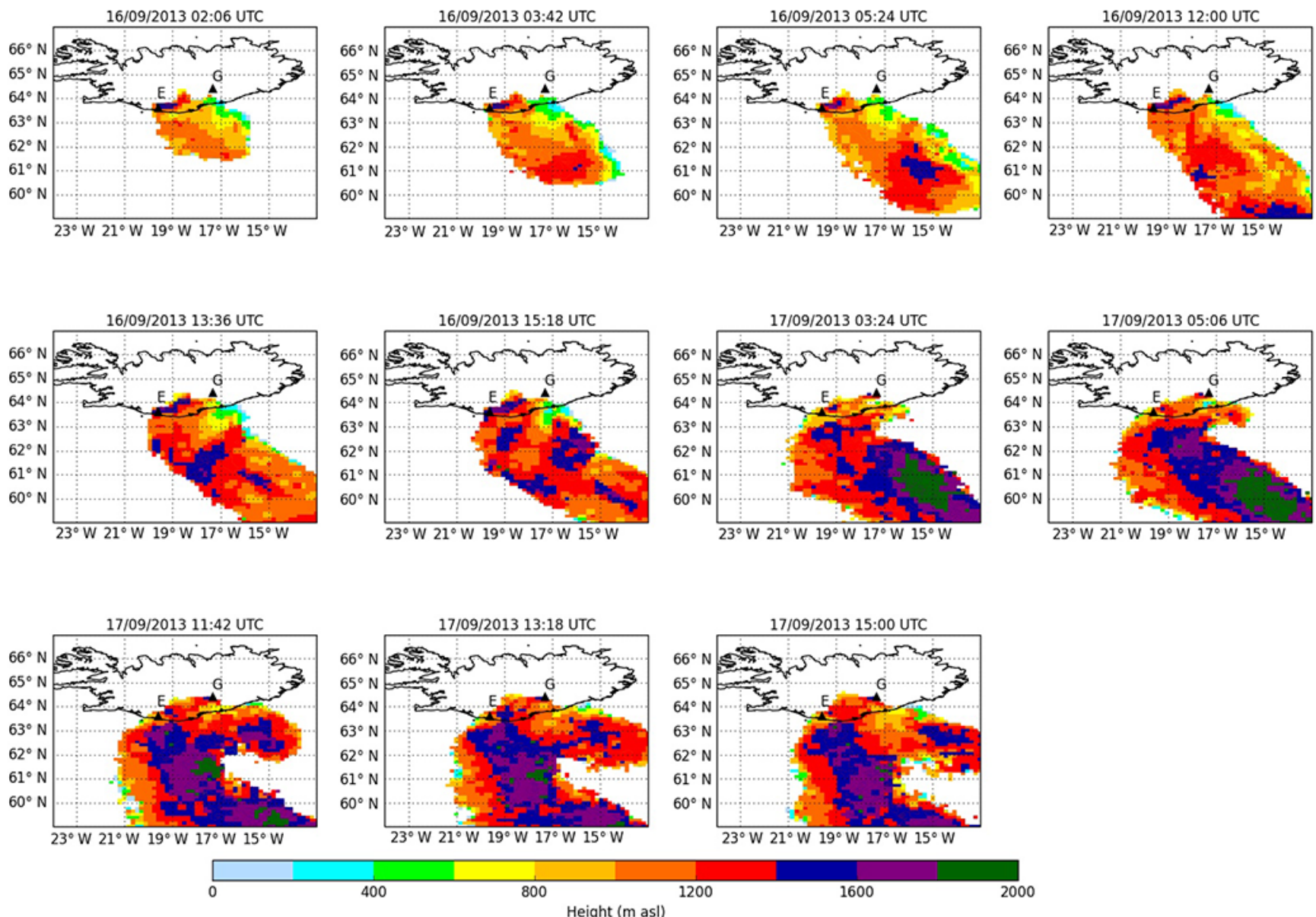

Figure 7. The maximum height of the modelled ash cloud using NAME at the times corresponding to the satellite retrievals. The locations of the volcanoes Eyjafjallajökull and Grímsvötn are indicated on the map by the E and G symbols respectively.
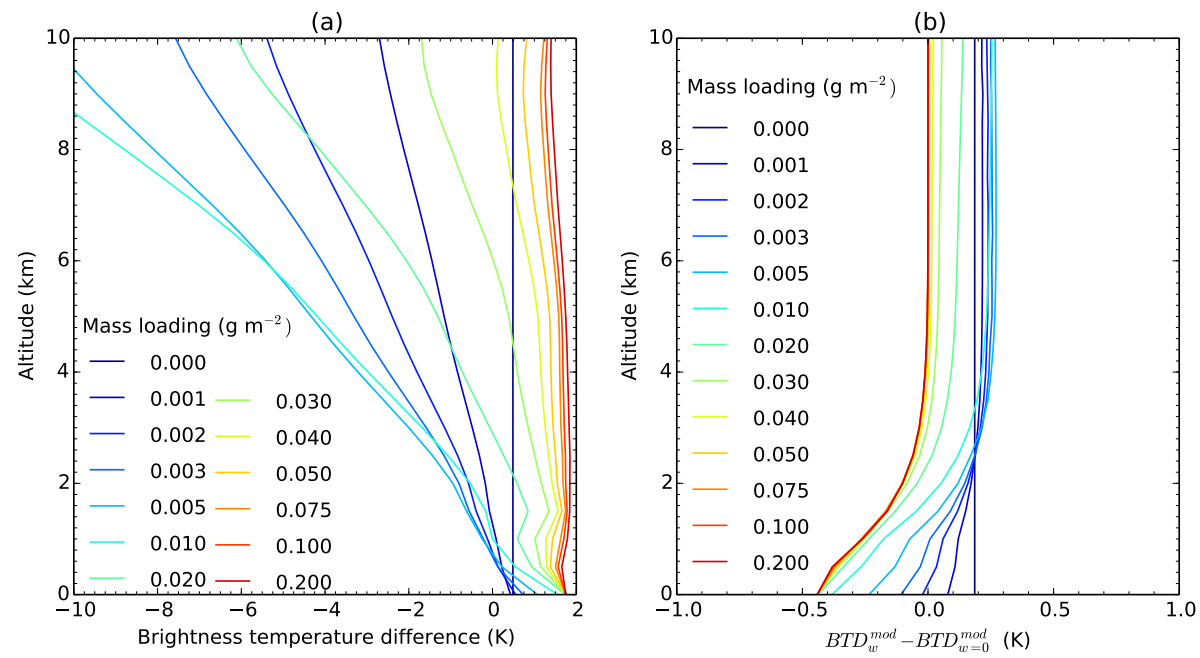

Figure 8. (a) The simulated brightness temperature difference between VIIRS bands M15 and M16, BTDV, for a $1 \mathrm{~km}$ thick ash layer as a function of ash layer top altitude. (b) The difference $\mathrm{BTD}_{\mathrm{w}}^{\mathrm{mod}}-\mathrm{BTD}_{\mathrm{w}=0.0}^{\mathrm{mod}}$ as a function of ash cloud top height. The curves represent varying ash mass loading $\left(\mathrm{g} \mathrm{m}^{-2}\right)$ and are given in the legend. 
on the plume heights predicted using NAME (Fig. 7). Ash particles were assumed to have a log-normal size distribution with effective radius $r_{\mathrm{e}}=2.0 \mu \mathrm{m}$ and geometric standard deviation $\sigma=2.0$, and nadir-viewing geometry was adopted. For an ash cloud at $8 \mathrm{~km}$ the BTDV decreases from about 0.5 to $-9 \mathrm{~K}$ when the ash mass loading increases from 0 to $0.01 \mathrm{~g} \mathrm{~m}^{-2}$. Further increasing the mass loading increases the BTD $v$ until the signal in the two channels saturate $\left(B_{T} D_{V}\right.$ of about $1.5 \mathrm{~K}$ ). This bowl-shaped behaviour is qualitatively similar to the behaviour shown in Fig. 2 of Wen and Rose (1994) and Fig. 2 of Prata and Prata (2012) for ash clouds at higher altitudes. Figure 8a further shows that, for ash cloud top heights above $2.0 \mathrm{~km}, \mathrm{BTD}_{\mathrm{V}}$ is negative for mass loadings less than $0.02 \mathrm{~g} \mathrm{~m}^{-2}$. Contrarily, BTDV $>0.0$ when the top of the ash cloud is between 0.5 and $2.0 \mathrm{~km}$ and mass loadings are $\geq 0.02 \mathrm{~g} \mathrm{~m}^{-2}$. As $16-17$ September 2013 resuspended ash cloud top is between 1 and $2 \mathrm{~km}$, a positive $\mathrm{BTD}_{\mathrm{V}}$ signal is therefore to be expected for volcanic ash, as seen in Fig. S6.

The absorption of radiation by atmospheric water vapour is larger at $12.0 \mu \mathrm{m}$ than at $11.0 \mu \mathrm{m}$. Hence, the presence of water vapour may reduce the volcanic ash $\mathrm{BTD}_{\mathrm{V}}$ signal. To remove the water vapour contribution to the BTDV signal, both empirical (Yu et al., 2002) and model-based (Corradini et al., 2008; Francis et al., 2012) correction procedures have been developed. Corradini et al. (2008) present the following correction procedure for water vapour absorption:

$\mathrm{BTD}_{\mathrm{V}}^{\mathrm{c}}=\mathrm{BTD}_{\mathrm{V}}-\mathrm{BTD}_{\mathrm{w}}$,

where $\mathrm{BTD}_{\mathrm{w}}$ is the BTD with water vapour and without ash:

$$
\begin{aligned}
& \mathrm{BTD}_{\mathrm{V}}=T_{15}-T_{16}, \\
& \mathrm{BTD}_{\mathrm{w}}=T_{15}^{\mathrm{m}}-T_{16}^{\mathrm{m}} .
\end{aligned}
$$

Here $T_{15,16}$ are the measured brightness temperatures in VIIRS bands M15 and M16 respectively, and $T_{15,16}^{\mathrm{m}}$ are the modelled brightness temperatures including only water vapour. Such a correction procedure assumes that radiation from the water vapour is independent from the radiation from the ash cloud. This assumption may be tested by simulating $\mathrm{BTD}_{\mathrm{V}}$ for various ash cloud heights and ash mass loadings with $\left(\mathrm{BTD}_{\mathrm{w}}^{\mathrm{mod}}\right)$ and without $\left(\mathrm{BTD}_{\mathrm{w}=0.0}^{\mathrm{mod}}\right)$ water vapour. The $\mathrm{BTD}_{\mathrm{w}=0.0}^{\mathrm{mod}}$ then resembles $\mathrm{BTD}_{\mathrm{V}}^{\mathrm{c}}$ in Eq. (2), whilst $\mathrm{BTD}_{\mathrm{w}}^{\text {mod }}$ resembles $\mathrm{BTD}_{\mathrm{V}}$. In view of Eq. (2), $\mathrm{BTD}_{\mathrm{w}}-\mathrm{BTD}_{\mathrm{w}=0.0}$ should then be constant.

Figure $8 \mathrm{~b}$ shows the difference $\mathrm{BTD}_{\mathrm{w}}^{\bmod }-\mathrm{BTD}_{\mathrm{w}=0.0}^{\bmod }$ for various ash mass loadings as a function of ash cloud top height. Above an ash cloud top altitude of $\sim 5.0 \mathrm{~km}$ the difference becomes constant for all mass loadings. However, the magnitude of the difference decreases with increasing mass loading. Below $5.0 \mathrm{~km}, \mathrm{BTD}_{\mathrm{w}}^{\bmod }-\mathrm{BTD}_{\mathrm{w}=0.0}^{\text {mod }}$ becomes smaller than the constant value above $5.0 \mathrm{~km}$. The deviation from the constant value increases with increasing ash cloud mass loading. Most of the water vapour is located in the lower troposphere. For an ash cloud above $5.0 \mathrm{~km}$ the radiation emitted by the water vapour must traverse the ash cloud similarly to the radiation emitted by the Earth's surface. It will contribute to $\mathrm{BTD}_{\mathrm{V}}$ in an additive manner; cf. Eq. (2). For an ash cloud below $5.0 \mathrm{~km}$ some of the water vapour will be above and some below the ash cloud. Radiation emitted by the water vapour above the ash cloud does not interact with the ash cloud, hence $\mathrm{BTD}_{\mathrm{w}}^{\text {mod }}-\mathrm{BTD}_{\mathrm{w}=0.0}^{\mathrm{mod}}$ decreases. For thick ash clouds the water vapour below the ash cloud does not contribute to the signal at the top of the atmosphere.

The 16-17 September 2013 resuspended ash cloud had a top height of about $1.0 \mathrm{~km}$ (Fig. 7). As is evident from Fig. 8 and the discussion above, any water vapour correction for an ash cloud at this altitude is not straightforward. Thus, no water vapour correction was applied before ash pixel identification. Rather, a customized ash detection scheme was applied; see the next section. For the ash mass loading retrieval the absorption of water vapour was included in the look-uptable (LUT) calculations using area-averaged ECMWF water vapour profiles; see Sect. 2.3 and Figs. S1-S4. It is noted that the presence of ice may give a positive BTD (see for example Rose et al., 1995). However, due to the ambient temperatures and the origin of the resuspended ash we rule out the presence of ice for the case studied here.

\subsection{Ash pixel detection}

Identification of ash pixels can normally be achieved by searching for pixels with $\mathrm{BTD}_{\mathrm{V}}<T_{\text {limit }}$, where $T_{\text {limit }}$ is zero. However, this limit assumes that the ash resides at high altitudes, such that the ash cloud temperature is sufficiently different from the surface temperature (Prata and Grant, 2001). The resuspended ash cloud during 16-17 September 2013 is easily identified in the RGB composites (Fig. 4). By comparing the RGB composites with the $\mathrm{BTD}_{\mathrm{V}}$ in Fig. S6, the resuspended ash cloud can be clearly identified in both the daytime and night-time images. However, due to the altitude of the resuspended ash cloud during this event, $\mathrm{BTD}_{\mathrm{V}}>0.0$ (see Sect. 3.2 and Fig. S6) and the normal threshold for identifying ash pixels cannot be applied. Instead pixels are identified as containing ash if

$$
\begin{aligned}
\left(\mathrm{BTD}_{\mathrm{V}}>\mathrm{BTD}_{\min }\right) & \wedge\left(\mathrm{BTD}_{\mathrm{V}}<\mathrm{BTD}_{\max }\right) \\
& \wedge\left(\mathrm{BT}_{15}>\mathrm{BT}_{15_{\min }}\right) .
\end{aligned}
$$

The values for $\mathrm{BTD}_{\min }$, $\mathrm{BTD}_{\max }$, and $\mathrm{BT}_{15_{\min }}$ are manually selected upon inspection for each scene and listed in Table 2. The BTD of the pixels identified as containing ash by this procedure is shown in Fig. 9. Through visual inspection of both the daytime (Fig. 4) and night-time images (Figs. S5 and S6) areas considered to contain ash are then defined by polygons, as shown in Figs. 4, S5, and S6 in an attempt to remove the obviously wrongly classified pixels. As discussed 
Table 2. VIIRS data used in this study. The study area is limited to the area delimited by $54-65^{\circ} \mathrm{N}, 12-26^{\circ} \mathrm{W}$. VIIRS data were ordered from http://sips.ssec.wisc.edu.

\begin{tabular}{lrrrrr}
\hline Date & $\begin{array}{r}\text { Time (UTC) } \\
\text { (start of scan) }\end{array}$ & $\begin{array}{r}\text { BTD }_{\min } \\
(\mathrm{K})\end{array}$ & $\begin{array}{r}\mathrm{BTD}_{\max } \\
(\mathrm{K})\end{array}$ & $\begin{array}{r}\mathrm{BT}_{\mathrm{M} 15_{\min }} \\
(\mathrm{K})\end{array}$ & $\begin{array}{r}\text { Total ash mass } \\
(\mathrm{Gg})\end{array}$ \\
\hline $16 / 09 / 2013$ & $02: 06$ & 0.0 & 0.8 & 272.0 & 17.78 \\
$16 / 09 / 2013$ & $03: 42$ & 0.0 & 0.5 & 275.0 & 11.80 \\
$16 / 09 / 2013$ & $05: 24$ & 0.0 & 0.8 & 270.0 & 17.05 \\
$16 / 09 / 2013$ & $12: 00$ & 0.0 & 0.8 & 270.0 & 19.52 \\
$16 / 09 / 2013$ & $13: 36$ & -0.1 & 0.45 & 270.0 & 14.63 \\
$16 / 09 / 2013$ & $15: 18$ & -0.1 & 1.0 & 270.0 & 24.89 \\
$17 / 09 / 2013$ & $03: 24$ & -0.1 & 0.7 & 275.0 & 26.58 \\
$17 / 09 / 2013$ & $05: 06$ & -0.1 & 0.8 & 275.0 & 8.75 \\
$17 / 09 / 2013$ & $11: 42$ & 0.3 & 1.0 & 275.0 & 13.76 \\
$17 / 09 / 2013$ & $13: 18$ & 0.0 & 0.5 & 275.0 & 8.67 \\
$17 / 09 / 2013$ & $15: 00$ & 0.0 & 1.0 & 275.0 & 8.05 \\
\hline
\end{tabular}

in the above section, the BTD signal depends on the atmospheric water vapour content and the resuspended ash height, and it requires cloud-free pixels. In addition the optical properties of the underlying surface must be accounted for. The detection method has potential for application in other cases but must be adapted to the situation being studied.

\subsection{Retrieval of ash properties and radiative transfer modelling}

From the satellite measurements the ash mass loading may be retrieved. Assuming spherical ash particles the mass loading, $M_{1}\left(\mathrm{~g} \mathrm{~m}^{-2}\right)$, is given by

$M_{1}=\rho \Delta z_{\mathrm{c}} \int_{0}^{\infty} \frac{4}{3} \pi r^{3} n(r) \mathrm{d} r$

where $\rho$ is the density of the ash particles, $\Delta z_{\mathrm{c}}$ is the ash cloud thickness, and $n(r)$ is the ash particle number density distribution. Assuming a log-normal size distribution,

$n(r)=\frac{N_{0}}{\sqrt{2 \pi}} \frac{1}{\ln (S)} \frac{1}{r} \exp \left[-\frac{\left(\ln r-\ln r_{0}\right)^{2}}{2 \ln ^{2}(S)}\right]$,

where $N_{0}$ is the total number of particles per unit volume, $S$ is the geometric standard deviation, and $r_{0}$ is the geometric mean radius, the mass loading simplifies to

$M_{1}=\rho \Delta z_{\mathrm{c}} \frac{4}{3} \pi N_{0} r_{\mathrm{e}}^{3} \exp \left(-\frac{6}{2} \ln ^{2} S\right)$

where $r_{\mathrm{e}}$ is the ash particle effective radius:

$r_{\mathrm{e}}=\frac{\int_{0}^{\infty} \pi r^{3} n(r) \mathrm{d} r}{\int_{0}^{\infty} \pi r^{2} n(r) \mathrm{d} r}$
It is noted that for the log-normal size distribution $r_{0}$ is related to $r_{\mathrm{e}}$ by

$r_{\mathrm{e}}=r_{0} \exp \left(\frac{5}{2} \ln ^{2} S\right)$

It is common to assume values for $S$ and $\rho$. For the case studied here, $\Delta z_{\mathrm{c}}$ is approximately known from temperature profiles and dispersion model calculations. Thus we have

$M_{1}=M_{1}\left(N_{0}, r_{\mathrm{e}}\right)$

The VIIRS infrared measurements provide BTs. The brightness temperature is a function of the state of the atmosphere and the underlying surface. This relationship is described by the radiative transfer equation. The state of the atmosphere is described by the temperature profile, the density profiles of relevant trace gases (for example $\mathrm{H}_{2} \mathrm{O}$ ), liquid water and ice cloud particle densities, and ash cloud particle densities. For infrared radiative transfer the temperature and emissivity of the underlying surface is also needed. In addition knowledge about the absorption and scattering across sections of the atmospheric constituents are required. For example the ash cloud optical depth $\tau_{\mathrm{a}}$ is given by

$\tau_{\mathrm{a}}(\lambda)=\Delta z_{\mathrm{c}} \int Q_{\mathrm{ext}}(\lambda, r) \pi r^{2} n(r) \mathrm{d} r$,

where $Q_{\text {ext }}(\lambda, r)$ is the ash cloud extinction efficiency as a function of wavelength $\lambda$ and radius $r$, and a vertically homogeneous ash cloud is assumed.

If we adopt best-guess values for the parameters listed in Table 3, the brightness temperature becomes a function of $N_{0}$ and $r_{\mathrm{e}}$ :

$\mathrm{BT}=\mathrm{BT}\left(N_{0}, r_{\mathrm{e}}\right)$. 


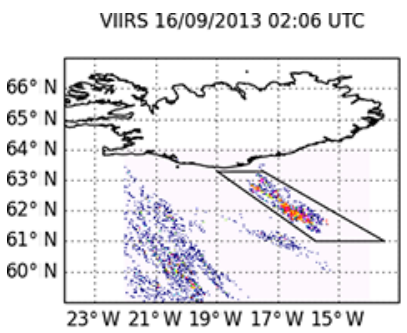

VIIRS $16 / 09 / 201313: 36$ UTC

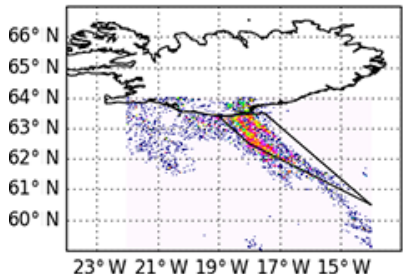

VIIRS 16/09/2013 03:42 UTC

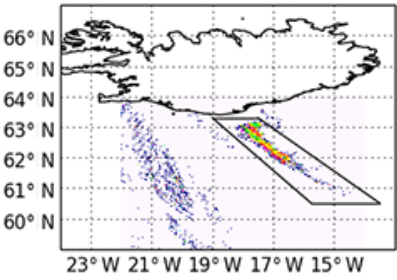

VIIRS $16 / 09 / 2013$ 15:18 UTC

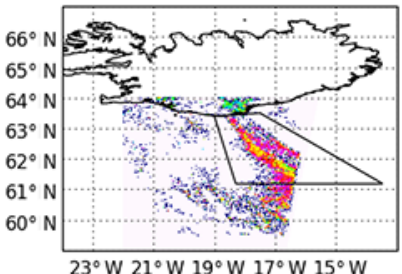

VIIRS 16/09/2013 05:24 UTC

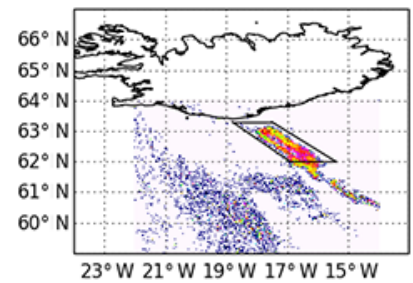

VIIRS $17 / 09 / 2013$ 03:24 UTC

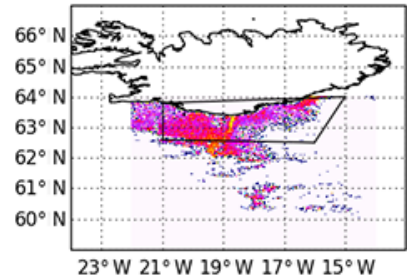

VIIRS $16 / 09 / 2013$ 12:00 UTC

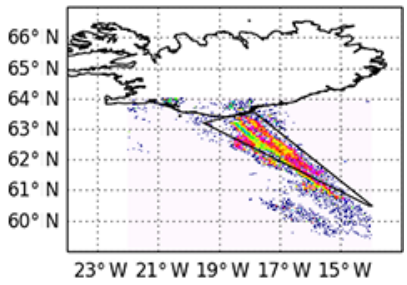

VIIRS $17 / 09 / 2013$ 05:06 UTC

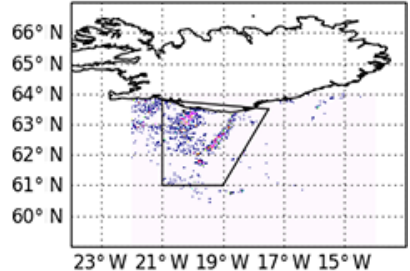

VIIRS 17/09/2013 11:42 UTC

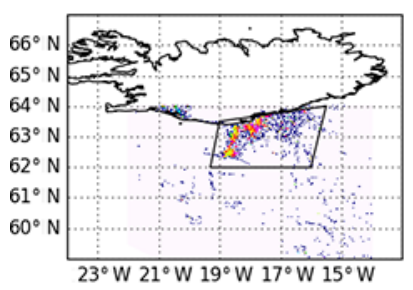

VIIRS 17/09/2013 13:18 UTC

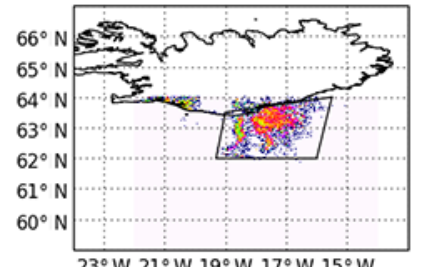

VIIRS $17 / 09 / 2013$ 15:00 UTC

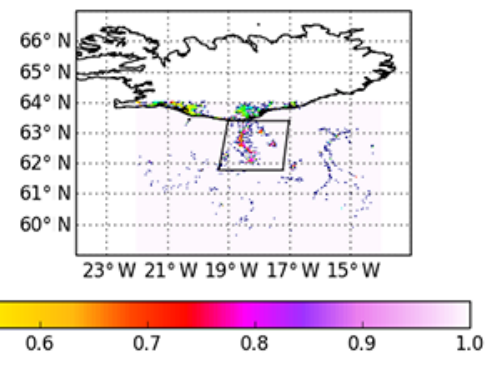

Figure 9. VIIRS BTDs for pixels identified as resuspended ash, 16-17 September 2013.

For the ash mass loading estimate we thus tabulate $\mathrm{BT}_{i}$ as a function of $N_{0}$ and $r_{\mathrm{e}}$ for $i=\mathrm{M} 15$ and M16. The tabulated values are then used to retrieve $N_{0}$ and $r_{\mathrm{e}}$ from measured $\mathrm{BT}_{\mathrm{M} 15}$ and $\mathrm{BT}_{\mathrm{M} 16}$, and finally the mass loading is calculated using Eq. (8).

The retrieval of $N_{0}$ and $r_{\mathrm{e}}$ is done using the Bayesian method described by Rodgers (2000). The cost function

$$
\begin{aligned}
J(\boldsymbol{x}) & =\left(\boldsymbol{x}-\boldsymbol{x}^{b}\right)^{T} \mathbf{B}^{-1}\left(\boldsymbol{x}-\boldsymbol{x}^{b}\right) \\
& +\left(\mathbf{y}^{\mathrm{ob}}-\mathbf{y}(\mathbf{x})\right)^{T} \mathbf{R}^{-1}\left(\mathbf{y}^{\mathrm{ob}}-\mathbf{y}(\mathbf{x})\right)
\end{aligned}
$$

is minimized using the Levenberg-Marquardt method. Here $\boldsymbol{x}$ is the atmospheric state vector consisting of the two elements $\left(N_{0}, r_{\mathrm{e}}\right), \boldsymbol{y}(\boldsymbol{x})$ is the brightness temperature calculated by the forward model for the atmospheric state $\boldsymbol{x}$, and $\boldsymbol{y}^{\mathrm{ob}}$ is the observed brightness temperatures of VIIRS bands M15 and M16. The prior estimate $\boldsymbol{x}^{b}$ is set to $N_{0}=10^{6}$ and $r_{\mathrm{e}}=1.0 \mu \mathrm{m}$. The background error covariance matrix is assumed to be diagonal with elements $\sigma_{N_{0}}^{2}=\left(10^{12}\right)^{2}$ and $\sigma_{r_{\mathrm{e}}}^{2}=(10 \mu \mathrm{m})^{2}$. The latter value is adopted from Francis et al. (2012). The diagonal elements of $\mathbf{B}$ are large, implying that the background state only provides a weak constraint on the retrieved values. The error covariance matrix $\mathbf{R}$ is also assumed to be diagonal. Its diagonal elements, $\sigma_{i}^{2}$, are the combined variance of the observational and forward-model variances. The observational variances are $\sigma_{\mathrm{M} 15}^{2}=(0.0028 \mathrm{~K})^{2}$ and $\sigma_{\mathrm{M} 16}^{2}=(0.0036 \mathrm{~K})^{2}$, and the forward-model variance is taken as $\sigma_{\mathrm{FM}}^{2}=(1.0 \mathrm{~K})^{2}$. This gives $\sigma_{i}^{2}=(1.0 \mathrm{~K})^{2}$.

The uvspec tool from the libRadtran radiative transfer package (Mayer and Kylling, 2005; Emde et al., 2011; www. libradtran.org) was used as the forward model to calculate VIIRS brightness temperatures for bands M15 and M16. A plane-parallel atmosphere was assumed, and the discreteordinate method was used to solve the radiative transfer equation with 16 streams (Stamnes et al., 1988; Buras et al., 2011). The ambient atmosphere profiles of temperature, pressure, and water vapour were taken from the averaged ECMWF profiles as described in Sect. 2.3 (Figs. S1-S4). The surface was assumed to be seawater with wavelength emissivity taken from http://www.icess.ucsb.edu/modis/EMIS/ html/seawater.html. For the gas absorption the REPTRAN 
Table 3. Assumed parameters and values used for the ash cloud retrieval. "ECMWF average" means the parameter is calculated from ECMWF analysis data averaged over the region for 16-17 September 2013. See text for more details.

\begin{tabular}{lll}
\hline Parameter & Value & Comment \\
\hline$\rho$ & $2300\left(\mathrm{~kg} \mathrm{~m}^{-3}\right)$ & Ash particle density \\
$T_{\mathrm{c}}$ & ECMWF average & Temperature of ash cloud top (Fig. S4) \\
$\Delta z_{\mathrm{c}}$ & $1000.0 \mathrm{~m}$ & Ash cloud thickness \\
$n(r)$ & Log-normal & Particle number density distribution \\
$S$ & 2.0 & Geometric standard deviation \\
$T_{\mathrm{S}}$ & ECMWF average & Surface temperature (Fig. S3) \\
$\epsilon$ & Seawater & Emissivity of surface \\
$T(z)$ & ECMWF average & Temperature profile (Fig. S4) \\
$Q_{\mathrm{ext}}$ & Andesite & Ash type \\
$\rho_{\mathrm{H}_{2} \mathrm{O}}(z)$ & ECMWF average & Water vapour profile (Fig. S2) \\
\hline
\end{tabular}

parameterization was used (Gasteiger et al., 2014). The resuspended ash was included as a plane-parallel layer. The ash particles were taken to be of andesite composition, and the refractive index was adopted from Pollack et al. (1973). The ash particles were assumed to be spherical in shape, and their optical properties were calculated using Mie theory. It is noted that porosity and non-sphericity of the ash particles may affect the electromagnetic IR radiation measured by VIIRS (Kylling et al., 2014). The uvspec model is computationally too slow to be used online in the retrieval; therefore LUTs were calculated as a function of $N_{0}$ and $r_{\mathrm{e}}$ for surface temperatures between 280 and $284 \mathrm{~K}$. Figure 10 shows the retrieved ash mass loading of the resuspended ash cloud for the areas identified as containing ash, and Table 2 gives the retrieved mass of ash in the atmosphere for each overpass. The location of the ash cloud agrees well with the forecasts using NAME (cf. Fig. 5). Quantifying the uncertainty on satellite retrievals of volcanic ash is non-trivial, and it includes uncertainties in the retrieval and uncertainties in the assumed parameters, such as the refractive index and particle size distribution (Mackie et al., 2014). Based on the work by Corradini et al. (2008) and in addition considering the uncertainty due to particle shape (Kylling et al., 2014), we assign an uncertainty of $\pm 50 \%$ to the total mass retrieved for each image.

\section{Quantifying the total mass of ash resuspended}

Here we determine the scaling coefficient $(K)$ for the emission rate $(F$, Eq. 1$)$ in the resuspension scheme in NAME. As we have data from only one OPC instrument, we are unable to perform a robust calibration with surface $\mathrm{PM}_{10}$ data. Instead we perform a calibration using the total column mass loadings of the remobilized ash cloud retrieved from VIIRS.

Figure 11 shows the frequency of binned total column mass loadings from the satellite retrievals and the NAME modelled mass loadings where $K$ is set to unity $\left(1 \mathrm{~g} \mathrm{~s}^{-1}\right)$. The mode of the VIIRS mass loadings varies with time during the
Table 4. Calculated fractional bias between VIIRS-retrieved total column mass loadings and modelled total column mass loadings where the emission rate in NAME is calibrated using the scaling coefficient $(K)$ derived from a peak-to-peak scaling to the VIIRS data.

\begin{tabular}{lrr}
\hline Time + Date & $K=1 \times 10^{3}$ & $K=1 \times 10^{4}$ \\
\hline 02:06 16/09/2013 & 0.89 & 1.85 \\
03:42 16/09/2013 & 1.14 & 1.89 \\
05:24 16/09/2013 & 0.22 & 1.71 \\
12:00 16/09/2013 & 0.40 & 1.75 \\
13:36 16/09/2013 & 0.51 & 1.78 \\
15:18 16/09/2013 & 0.70 & 1.82 \\
03:24 17/09/2013 & -0.61 & 1.37 \\
$05: 0617 / 09 / 2013$ & 0.82 & 1.84 \\
$11: 4217 / 09 / 2013$ & 0.40 & 1.75 \\
$13: 1817 / 09 / 2013$ & 0.77 & 1.83 \\
$15: 0017 / 09 / 2013$ & 1.16 & 1.90 \\
\hline
\end{tabular}

event, from $10^{-1}-10^{0}$ to $10^{0}-10^{1} \mathrm{~g} \mathrm{~m}^{-2}$; this variation includes the uncertainty associated with the retrieval. The uncalibrated modelled total column mass loadings have a mode at $10^{-4}-10^{-3} \mathrm{~g} \mathrm{~m}^{-2}$. Considering the difference in the mode of the VIIRS-retrieved mass loadings and the model output at each retrieval time, this suggests that we need to apply a scaling of between $K=1 \times 10^{3}$ and $1 \times 10^{4}$ to the emission rate in the resuspension scheme in NAME to match the observed mass loadings in the atmosphere.

Simulated mass loadings using these calibration factors are given in Fig. 12. The performance of the calibration factors are assessed by calculating the fractional bias between the satellite-retrieved and the modelled total column mass loadings within the polygons (Table 4). The fractional bias is a measure of the mean bias and indicates over- or underestimation of the model output: values range between -2 and +2 , a positive value represents over-prediction of the model with respect to the VIIRS-retrieved mass loadings, a negative value represents under-prediction; and a value of 0 represents 
VIIRS 16/09/2013 02:06 (UTC)

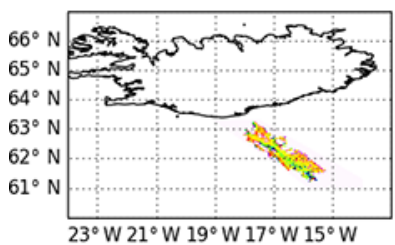

VIIRS 16/09/2013 03:42 (UTC)

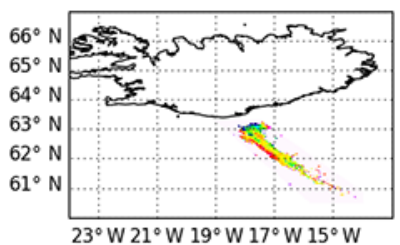

VIIRS 16/09/2013 05:24 (UTC)

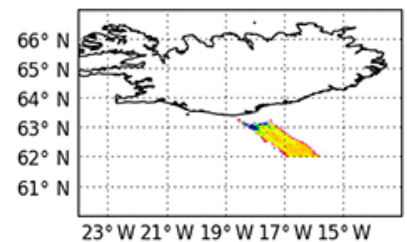

VIIRS 16/09/2013 12:00 (UTC)

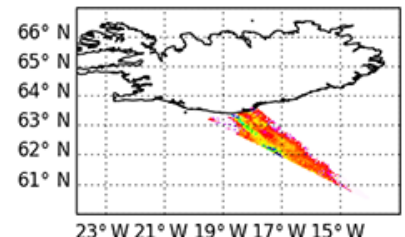

VIIRS 16/09/2013 13:36 (UTC)

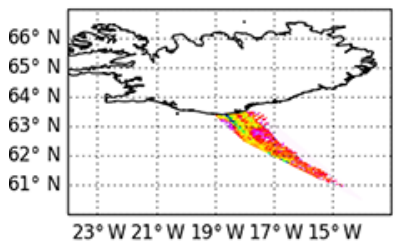

VIIRS 16/09/2013 15:18 (UTC)

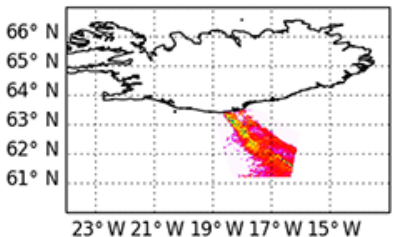

VIIRS 17/09/2013 03:24 (UTC)

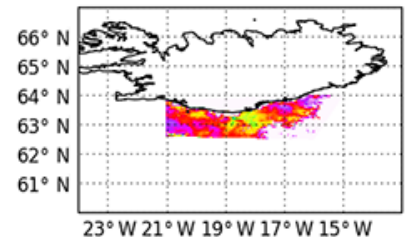

VIIRS 17/09/2013 05:06 (UTC)

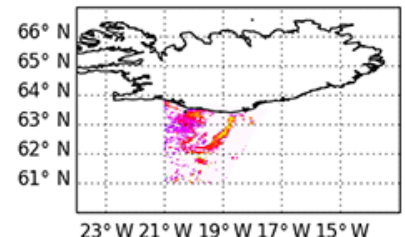

VIIRS 17/09/2013 11:42 (UTC)

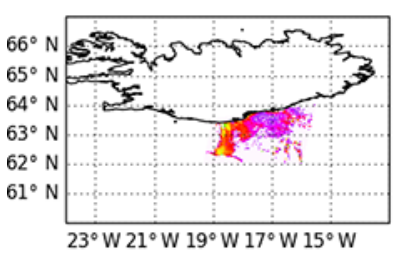

VIIRS 17/09/2013 13:18 (UTC)

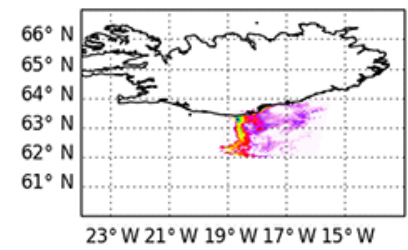

VIIRS 17/09/2013 15:00 (UTC)

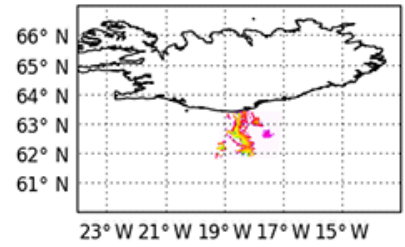

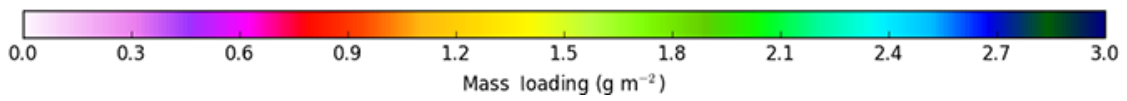

Figure 10. The resuspended ash mass loading retrieved from VIIRS infrared bands M15 and M16 for the areas identifed as containing ash.

a perfect match. Scaling the source strength by $K=1 \times 10^{4}$ systematically overestimates mass loadings, whereas using $K=1 \times 10^{3}$ results in a better match to the satellite retrievals. This is still the case when we consider that the retrieved mass loadings have an uncertainty of $\pm 50 \%$.

Summing the mass loadings from each VIIRS retrieval (Table 2) gives a total observed mass of remobilized ash of $0.17 \mathrm{Tg}$. This represents contributions only from the mass in the atmosphere at the time of each overpass and may doublecount between retrievals. Using the modelled emission rates, scaled by $K=1 \times 10^{3}$, the total mass of ash remobilized from the Eyjafjallajökull 2010 and Grímsvötn 2011 deposits between 00:00 UTC on 16 September 2013 and 00:00 UTC on 18 September 2013 is $\sim 0.2 \mathrm{Tg}$.

\section{Discussion}

The total mass of ash erupted from Eyjafjallajökull in 2010 was estimated from ground surveys and remote sensing to be $384 \pm 96 \mathrm{Tg}$ (Gudmundsson et al., 2012). Calculated estimates using plume rise models are also found to lie within the error bounds of this observational estimate (Devenish, 2016). Preliminary results from mapping the Grímsvötn 2011 fall deposits indicate that the bulk volume of ash from this eruption is 2-3 times larger (Gudmundsson et al., 2012). We estimate that $\sim 0.2 \mathrm{Tg}$ of ash was remobilized during 16-17 September 2013.

The calibration applied in this study is uniquely related to the event studied and the source areas defined, but this approach can be used to consider how the emission rate of resuspension has varied with time since the ash was deposited. The calibrated emission flux of $K=1 \times 10^{3}$ is lower than the original calibration determined by Leadbetter et al. (2012), $K=1.1 \times 10^{7}$ (taking an emission flux in grams), for the Eyjafjallajökull ash source in 2010. This suggests that resuspension rates had declined by 2013, perhaps due to depletion and compaction of the ash with time since it was deposited and/or re-growth of vegetation. However, the retrieved mass loadings from VIIRS and the calibrated modelled mass loadings show that the resuspended ash cloud still contained significant quantities of ash. Dividing the calculated total mass of ash resuspended over the emission time period $(48 \mathrm{~h})$, we cal- 

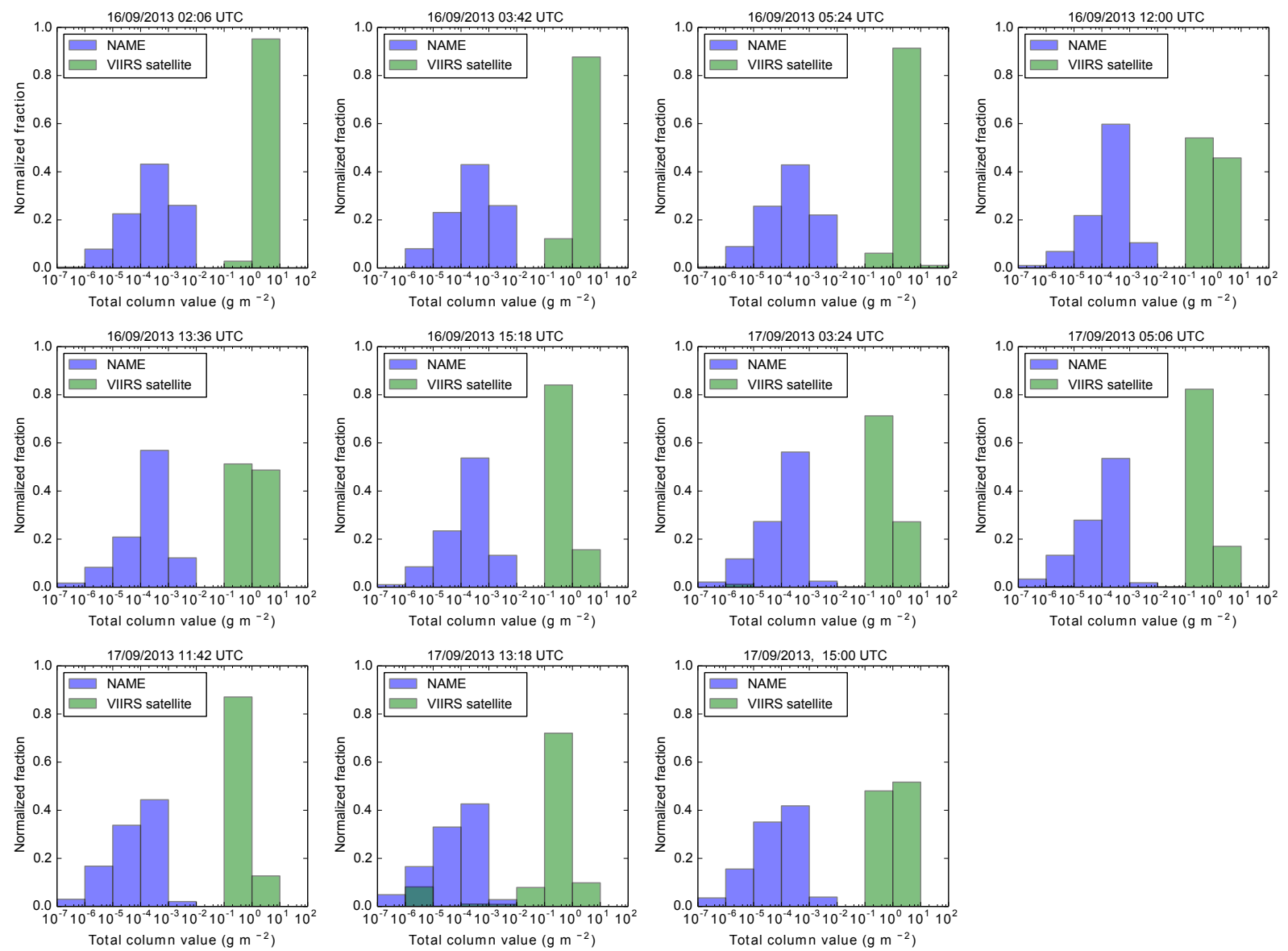

Figure 11. Comparing the frequency of binned total column mass loadings of the resuspended ash cloud modelled using NAME with an un-calibrated source strength to those retrieved from VIIRS during 16-17 September 2013.

culate an average emission rate of $1.04 \times 10^{3} \mathrm{~kg} \mathrm{~s}^{-1}$. This is equivalent to the minimum calculated eruption rates of tephra from Eyjafjallajökull 2010 using plume rise models, which range between $10^{3}$ and $10^{6} \mathrm{~kg} \mathrm{~s}^{-1}$ over the 39-day eruption (Woodhouse et al., 2012; Devenish, 2013). The magnitude of the retrieved ash mass loading in individual scenes from the VIIRS data is also comparable in magnitude to those determined by Prata and Prata (2012) using SEVIRI of the distal ash cloud from the eruption of Eyjafjallajökull in 2010 over the southern North Sea on 17 May 2010. This suggests that remobilization of ash deposits can produce ash clouds with mass loadings equivalent to those observed from explosive volcanic eruptions. One important distinction is that the buoyant ash plume generated from the eruption of Eyjafjallajökull released ash to altitudes up to $10 \mathrm{~km}$ a.s.l., and the resulting ash cloud was consequently transported by upperair winds. In contrast, resuspended ash, remobilized from deposits, is necessarily closer to the surface, and during 16-17 September 2013 the ash was trapped below a temperature inversion at $<2 \mathrm{~km}$ a.s.l., restricting further vertical dispersion. Ash sedimenting from a low-altitude resuspended ash cloud will be deposited more quickly than ash which is released at upper levels, as it does not have as far to fall and because it will be rained out by precipitation from clouds formed above the ash layer.

Liu et al. (2014) measured the PSD of resuspended ash deposited in Reykjavik during 6-7 March 2013 following a significant remobilization event of the Eyjafjallajökull 2010 and Grímsvötn 2011 deposits. Most of the mass was contained within the $32-63 \mu \mathrm{m}$ size fraction, and $<10 \%$ of the total mass was on particles with diameter $<10 \mu \mathrm{m}$. Here we have considered particles with diameter $\leq 10 \mu \mathrm{m}$ only, to be consistent with the particle size range the satellite retrievals are most sensitive to. No observations of the PSD of the remobilized ash cloud were made during 16-17 September 2013. Taking the PSD from Liu et al. (2014) suggests that our calculated remobilized mass of $0.2 \mathrm{Tg}$ for this event may represent a fraction of the total mass actually resuspended.

We have used the extent of tephra deposits defined immediately after the eruptions of Eyjafjallajökull in 2010 and Grímsvötn in 2011 to identify the potential source area from which ash can be resuspended. This does not consider how the deposits may have been modified since they were formed. Compaction and cementation processes increase deposit co- 
(a)

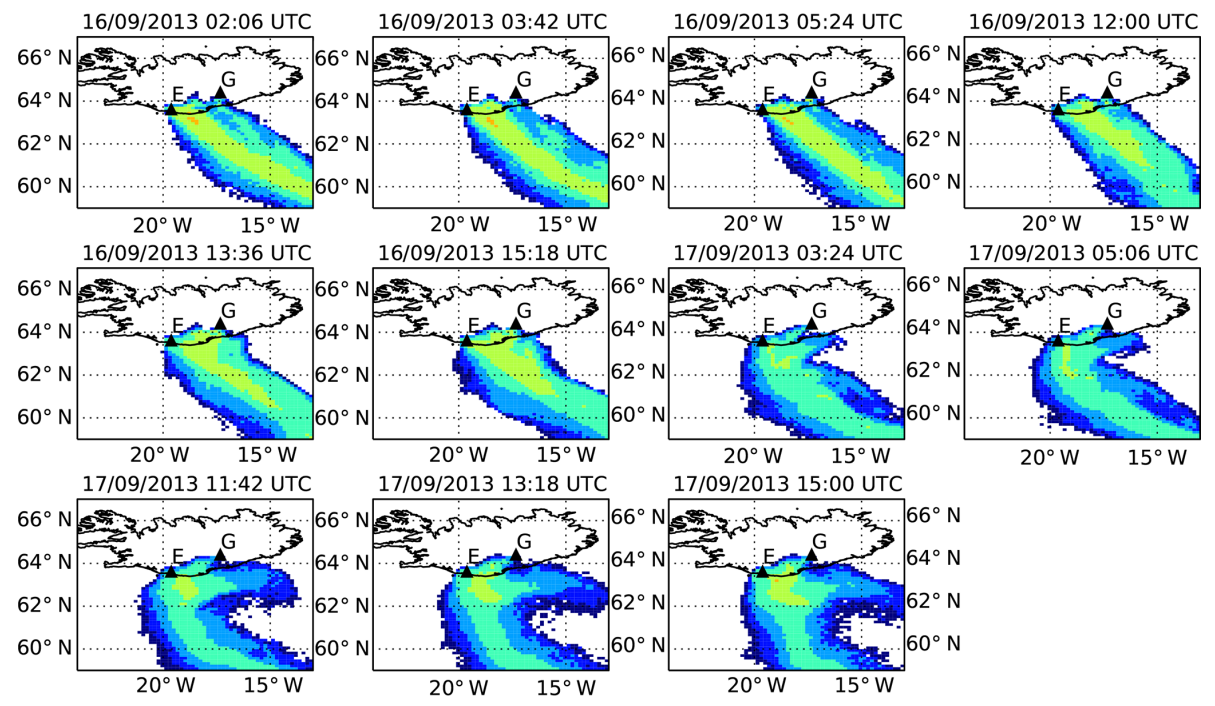

(b)

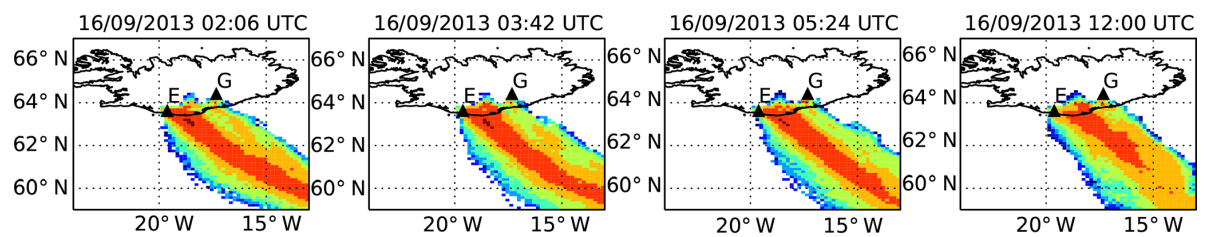

16/09/2013 13:36 UTC 16/09/2013 15:18 UTC

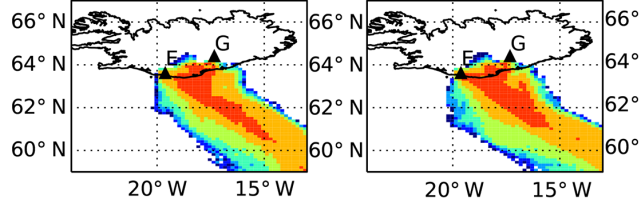

09/2013 11:42 UTC
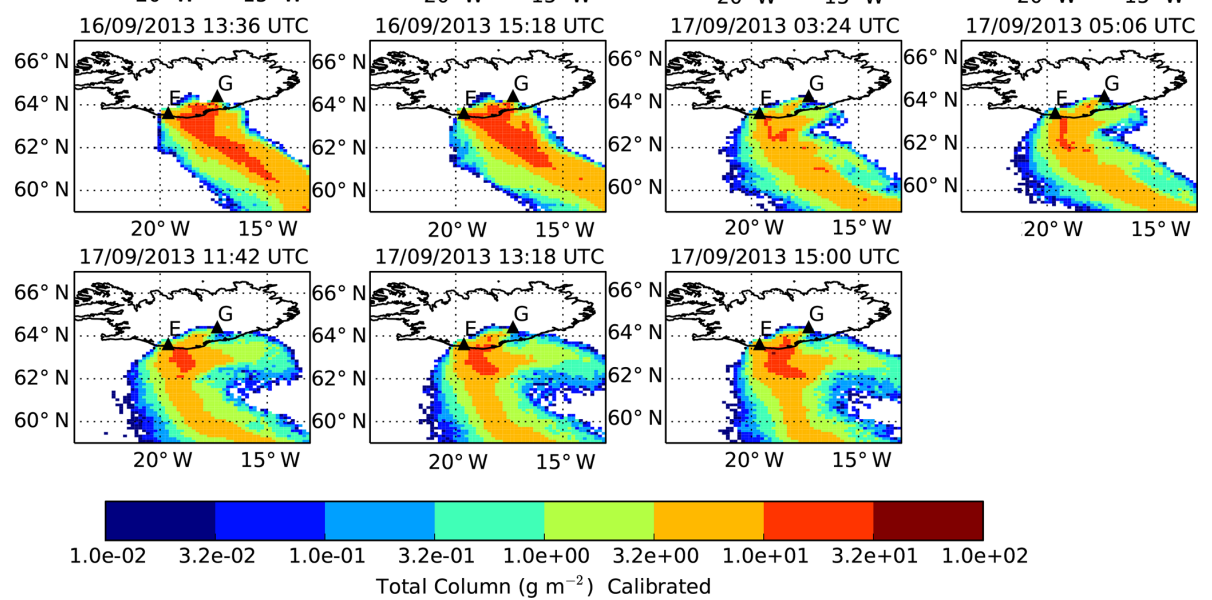

Figure 12. Modelled $1 \mathrm{~h}$ averaged total column mass loadings $\left(\mathrm{g} \mathrm{m}^{-2}\right)$, where the source strength in NAME is calibrated using the scaling coefficient determined from the peak-to-peak scaling to the satellite-retrieved total column values (a) $K=1 \times 10^{3}$ and (b) $K=1 \times 10^{4}$. The locations of the volcanoes Eyjafjallajökull and Grímsvötn are indicated on the map by the E and G symbols respectively.

hesion and can reduce the emission flux of particles. Here, we have applied the same scaling coefficient to both the Eyjafjallajökull and Grímsvötn deposits, which could underestimate the flux from the younger Grímsvötn deposits and overestimate the flux of particles from the older Eyjafjallajökull deposits (Liu et al., 2014). Deposits are also re-distributed as ash is resuspended, advected, and re-deposited. Jökulhlaups (sub-glacial floods) can also transport large volumes of ash which is then re-deposited on outwash planes (sandurs).
The sandur planes represent large areas of unstable sediments and are known to be an additional source of remobilized particles across Iceland (Arnalds et al., 2001, 2014; DagssonWaldhauserova et al., 2014; Arnalds et al., 2016). Arnalds et al. (2014) calculated the total emission from a remobilized "dust storm" on 25 May 2012 in Dyngjusandur, a large glacio-fluvial plain north of Vatnajökull, to be $3.65 \times 10^{5} \mathrm{t}$ $(\sim 0.3 \mathrm{Tg})$. The calculated emission is based on measurements of the horizontal extent of the plume and visibility 
(weather) observations, which were validated with MODIS satellite imagery. More recently Dagsson-Waldhauserova et al. (2016) estimated the total mass of dust resuspended during two storms in south-west Iceland, on 15 June 2015 and 4 August 2015, from observations of the horizontal extent of the plume and visibility measurements to be $\sim 0.18$ and $\sim 0.28 \mathrm{Tg}$ respectively. These masses are comparable to the value calculated here. The VIIRS satellite imagery of the resuspended ash cloud during 16-17 September 2013 clearly indicates that the source of the remobilized ash cloud is over southern Iceland, and the two distinct plumes observed in the visible imagery (Fig. 4) suggest that both the Eyjafjallajökull and Grímsvötn deposits are the primary sources of the remobilized ash. The good agreement between the modelled and observed location and timing of the resuspended ash cloud gives us confidence that our source areas are well defined (Fig. 5). However, the sandur planes on the south coast at Mýrdalssandur and Skeiðarársandur may also have been an additional source of ash which has not been accounted for. It is not yet understood whether the mechanism of resuspension, and hence the rate at which particles are remobilized, from the sandur planes differs to that from the tephra deposits. Applying the same calibration coefficient to a larger source area, to include the sandur plains, would increase the total modelled emission flux.

\section{Conclusions}

Volcanic ash continues to pose a hazard to local populations and airports for years after an eruption as particles are remobilized from deposits. NAME, which includes a resuspension scheme for volcanic ash, is used to provide daily forecasts of possible remobilized ash storms in Iceland. When a significant resuspension event is anticipated, the local population is informed by the IMO via their routine weather forecasts. To forecast resuspended ash storms with dispersion models, the source (deposit) areas and the emission rate of the particles must be known. This is challenging because deposits continuously evolve as they are remobilized, compacted, and revegetated. Here we have applied a novel technique to constrain the emission rate in the resuspension scheme in NAME using retrieved mass loadings of a resuspended ash cloud from satellite imagery. The simple approach presented here, in which the emission rate is scaled by a calibration factor $(K)$ to observations, is very versatile. It allows the user to update the emission scheme with time, matching to observations as deposits evolve. We find that a calibration factor of $K=1 \times 10^{3}$ best represents ash mass loadings of a resuspended ash cloud observed during 16-17 September 2013 over southern Iceland. Using this calibration factor, we estimate that a total of $\sim 0.2 \mathrm{Tg}$ of ash was remobilized during this event.
Data availability. VIIRS data are available from the NASA VIIRS Atmosphere Science Investigator-led Processing System (SIPS; sips.ssec.wisc.edu/). Please see Supplement S7 for the shell script used to retrieve the VIIRS data. NAME, meteorological data, processed data, analysis results, and analysis and visualization codes are available upon request from the Met Office (email to atmospheric.dispersion@metoffice.gov.uk).

\section{The Supplement related to this article is available online at doi:10.5194/acp-17-4401-2017-supplement.}

Author contributions. Frances Beckett performed the NAME simulations and wrote most of the paper. Arve Kylling produced the satellite imagery, performed the satellite retrievals and the radiative transfer modelling, and provided significant input to writing the manuscript. Guðmunda Sigurðardóttir and Sibylle von Löwis provided the OPC data and advice on interpreting it. Claire Witham provided advice and guidance on the NAME modelling and calibration of the source strength.

Competing interests. The authors declare that they have no conflict of interest.

Acknowledgements. Frances Beckett would like to thank Ayoe Hansen (ADAQ, Met Office) for her help in plotting the tephigrams, Michael Lawrence (EMARC Meteorologist, Met Office) for his advise on interpreting them, and Susan Leadbetter and Matthew Hort (ADAQ, Met Office) for their reviews of a draft of this manuscript. Arve Kylling acknowledges support from the Norwegian Research Council (contract 224716/E10). Funding for this research was provided by the FP7 project FUTUREVOLC "A European volcanological supersite in Iceland: a monitoring system and network for the future" (grant agreement no. 308377).

Edited by: G. Vaughan

Reviewed by: M. Watson and two anonymous referees

\section{References}

Arnalds, O., Gisladottir, F. O., and Sigurjonsson, H.: Sandy deserts of Iceland: an overview, J. Arid Environ., 47, 359-371, 2001.

Arnalds, O., Thorarinsdottir, E., Thorsson, J., and DagssonWaldhauserova, P.: An extreme wind erosion event of the fresh Eyjafjallajökull 2010 volcanic ash, Nature, 3, 1257, doi:10.1038/srep01257, 2013.

Arnalds, O., Olafsson, H., and Dagsson-Waldhauserova, P.: Quantification of iron-rich volcanogenic dust emissions and deposition over the ocean from Icelandic dust sources, Biogeosciences, 11, 6623-6632, doi:10.5194/bg-11-6623-2014, 2014.

Arnalds, O., Dagsson-Waldhauserova, P., and Olafsson, H.: The Icelandic volcanic aeolian environment: Processes and impacts - A review, Aeolian Research, 20, 176-195, 2016. 
Athanassiadou, M., Flocas, H., Harrison, M., Hort, M., Witham, C., and Millington, S.: The dust event of 17 April 2005 over Athens, Greece, Weather, 61, 125-131, 2006.

Buras, R., Dowling, T., and Emde, C.: New secondary-scattering correction in DISORT with increased efficiency for forward scattering, J. Quant. Spectrosc. Ra., 112, 2028-2034, doi:10.1016/j.jqsrt.2011.03.019, 2011.

Bush, M., Bell, S., Christidis, N., Renshaw, R., MacPherson, B., and Wilson, C.: Development of the North Atlantic European Model (NAE) into an operational model, Forecasting Research Technical Report, Met Office, 470, 2006.

Carey, R., Houghton, B., and Thordarson, T.: Tephra dispersal and eruption dynamics of wet and dry phases of the 1875 eruption of Askja Volcano, Iceland, B. Volcanol., 72, 259-278, 2010.

Corradini, S., Spinette, C., Carboni, E., Tirelli, C., Buongiorno, M. F., Pugnaghi, S., and Gangale, G.: Mt. Etna tropospheric ash retrieval and sensitivity analysis using Moderate Resolution Imaging Spectroradiometer Measurements, J. Appl. Remote Sens., 2, 674, doi:10.1117/1.3046, 2008.

Dagsson-Waldhauserova, P., Arnalds, O., and Olafsson, H.: Longterm variability of dust events in Iceland (1949-2011), Atmos. Chem. Phys., 14, 13411-13422, doi:10.5194/acp-14-134112014, 2014.

Dagsson-Waldhauserova, P., Magnusdottir, A., Olafsson, H., and Arnalds, O.: The spatial variation of dust particulate matter concentrations during two Icelandic dust storms in 2015, Atmosphere, 7, 77, doi:10.3390/atmos7060077, 2016.

Davies, T., Cullen, M., Malcolm, A., Mawson, M., Staniforth, A., White, A., and Wood, N. A.: A new dynamical core for the Met Office's global and regional modelling of the atmosphere, Q. J. Roy. Meteor. Soc., 131, 1759-1782, 2005.

Devenish, B.: Using simple plume models to refine the source mass flux of volcanic eruptions according to atmospheric conditions, J. Volcanol. Geoth. Res., 256, 118-127, doi:10.1016/j.jvolgeores.2013.02.015, 2013.

Devenish, B.: Estimating the total mass emitted by the eruption of Eyjafjallajökull in 2010 using plumerise models, J. Volcanol. Geoth. Res., 326, 114-119, doi:10.1016/j.jvolgeores.2016.01.005, 2016.

Emde, C., Buras, R., and Mayer, B.: ALIS: An efficient method to compute high spectral resolution polarized solar radiances using the Monte Carlo approach, J. Quant. Spectrosc. Ra., 112, 16221631, 2011.

Folch, A., Mingari, L., Osores, M. S., and Collini, E.: Modeling volcanic ash resuspension - application to the 14-18 October 2011 outbreak episode in central Patagonia, Argentina, Nat. Hazards Earth Syst. Sci., 14, 119-133, doi:10.5194/nhess-14-119-2014, 2014.

Francis, P. N., Cooke, M. C., and Saunders, R. W.: Retrieval of physical properties of volcanic ash using Meteosat: A case study from the 2010 Eyjafjallajökull eruption, J. Geophys. Res.-Atmos., 117, D00U09, doi:10.1029/2011JD016788, 2012.

Gasteiger, J., Emde, C., Mayer, B., Buras, R., Buehler, S., and Lemke, O.: Representative wavelengths absorption parameterization applied to satellite channels and spectral bands, J. Quant. Spectrosc. Ra., 148, 99-115, doi:10.1016/j.jqsrt.2014.06.024, 2014.

Gillette, D. and Passi, R.: Modelling dust emission caused by wind erosion, J. Geophys. Res., 93, 14233-14242, 1988.
Gislason, S., Hassenkam, T., Nedel, S., Bovet, N., Eiriksdottir, E. S. Alfredsson, H. A., Hem, C. P., Balogh, Z. I., Dideriksen, K., Oskarsson, N., Sigfusson, B., Larsen, G., and S., S. S. L.: Characterization of Eyjafjallajökull volcanic ash particles and a protocol for rapid risk assessment, P. Natl. Acad. Sci. USA, 108, 7307 $7312,2011$.

Gu, Y., Rose, W. I., and Bluth, G. J. S.: Retrieval of mass and sizes of particles in sandstorms using two MODIS IR bands: A case study of April 7, 2001 sandstorm in China, Geophys. Res. Lett., 30, 1805, doi:10.1029/2003GL017405, 2003.

Gudmundsson, M., Thordarson, T., Hoskuldsson, A., Larsen, G., Bjornsson, H., Prata, F., Oddsson, B., Magnusson, E., Hognadottir, T., Petersen, G., Hayward, C., Stevenson, J., and Jonsdottir, I.: Ash generation and distribution from the April-May 2010 eruption of Eyjafjallajökull, Iceland, Sci. Rep., 2, 572, doi:10.1038/srep00572, 2012.

Guffanti, M., Mayberry, G., Casadevall, T., and Wunderman, R.: Volcanic hazards to airports, Nat. Hazards, 51, 287-302, 2009.

Horwell, C. and Baxter, P.: The respiratory health hazards of volcanic ash: a review for volcanic risk mitigation, B. Volcanol., 69, doi:10.1007/s00445-006-0052-y, 2006.

Hreinsdóttir, S., Sigmundsson, F., Roberts, M. J., Björnsson, H., Grapenthin, R., Arason, P., Árnadóttir, T., Hólmjárn, J., Geirsson, H., Bennett, R. A., Gudmundsson, M. T., Oddsson, B., Ófeigsson, B. G., Villemin, T., Jónsson, T., Sturkell, E., Höskuldsson, Á., Larsen, G., Thordarson, T., and Óladóttir, B. A.: Volcanic plume height correlated with magma-pressure change at Grímsvötn Volcano, Iceland, Nat. Geosci., 7, 214-218, doi:10.1038/NGEO2044, 2014.

Jones, A., Thomson, D., Hort, M., and Devenish, B.: The UK Met Office's next-generation atmospheric dispersion model, NAME III, in: Air Pollution Modelling and its Application, edited by: Borrego, C. and Norman, A.-L., Springer, 580-589, 2007.

Jude-Eton, T., Thordarson, T., Gudmundsson, M., and Oddsson, B.: Dynamics, stratigraphy and proximal dispersal of supraglacial tephra during the ice-confined 2004 eruption at Grímsvötn Volcano, Iceland, B. Volcanol., 74, 1057-1082, 2012.

Kylling, A., Kahnert, M., Lindqvist, H., and Nousiainen, T.: Volcanic ash infrared signature: porous non-spherical ash particle shapes compared to homogeneous spherical ash particles, Atmos. Meas. Tech., 7, 919-929, doi:10.5194/amt-7-919-2014, 2014.

Larsen, G., Newton, A., Dugmore, A., and Vilmundardóttir, E.: Geochemistry, dispersal, volumes and chronology of Holocene silicic tephra layers from the Katla volcanic system, Iceland, J. Quaternary Sci., 16, 119-132, 2001.

Leadbetter, S., Hort, M., von Löwis, S., Weber, K., and Witham, C.: Modelling the resuspension of ash deposited during the eruption of Eyjafjallajökull in spring 2010, J. Geophys. Res., 117, D00U10, doi:10.1029/2011JD016802, 2012.

Liu, E., Cashman, K., Beckett, F., Witham, C., Leadbetter, S., Hort, M., and Gudmundsson, S.: Ash mists and brown snow: Remobilization of volcanic ash from recent Icelandic eruptions., J. Geophys. Res.-Atmos., 119, doi:10.1002/2014JD021598, 2014.

Mackie, S., Millington, S., and Watson, I.: How assumed composition affects the interpretation of satellite observations of volcanic ash, Meteorol. Appl., 21, 20-29, 2014. 
Maryon, R., Ryall, D., and Malcolm, A.: The NAME 4 Dispersion Model: Science Documentation, Met O Turbulence and Diffusion Note, 262 pp., 1999.

Mayer, B. and Kylling, A.: Technical note: The libRadtran software package for radiative transfer calculations - description and examples of use, Atmos. Chem. Phys., 5, 1855-1877, doi:10.5194/acp-5-1855-2005, 2005.

Novak, M. A. M., Watson, I. M., Delgado-Granados, H., Rose, W. I., Cárdenas-Gonzáles, L., and Realmuto, V. J.: Volcanic emissions from Popcatépetl volcano, Mexico, quantified using Moderate Resolution Imaging Spectroradiometer (MODIS) infrared data: A case study of the December 2000-January 2001 emissions, J. Volcanol. Geoth. Res., 170, 76-85, 2008.

Olsson, J., Stipp, S., Dalby, K., and Gislason, S.: Rapid release of metal salts and nutrients from the 2011 Grímsvötn, Iceland volcanic ash, Geochim. Cosmochim. Ac., 123, 134-149, 2013.

Pollack, J. B., Toon, O. B., and Khare, B. N.: Optical properties of some terrestrial rocks and glasses, ICARUS, 19, 372-389, 1973.

Prata, A. J.: Infrared radiative transfer calculations for volcanic ash clouds, Geophys. Res. Lett., 16, 1293-1296, 1989.

Prata, A. J. and Grant, I. F.: Retrieval of microphysical and morphological properties of volcanic ash plumes from satellite data: Application to Mt Ruapehu, New Zealand, Q. J. Roy. Meteor. Soc., 127, 2153-2179, 2001.

Prata, A. J. and Prata, A. T.: Eyjafjallajökull volcanic ash concentrations determined using Spin Enhanced Visible and Infrared Imager measurements, J. Geophys. Res., 117, D00U23, doi:10.1029/2011JD016800, 2012.

Remer, L. A., Kaufman, Y. J., Tanrě, D., Mattoo, S., Chu, D. A., Martins, J. V., Li, R.-R., Ichoku, C., Levy, R. C., Kleidman, R. G., Eck, T. F., Vermote, E., and Holben, B. N.: The MODIS Aerosol Algorithm, Products, and Validation, J. Atmos. Sci., 62, 947-973, doi:10.1175/JAS3385.1, 2005.

Rodgers, C. D.: Inverse methods for atmospheric sounding, Theory and practice, World Scientific Publishing Co. Ptc. Ltd., 2000.

Rose, W. I., Delene, D. J., Schneider, D. J., Bluth, G. J. S., Krueger, A. J., Sprod, I., McKee, C., Davies, H. L., and Ernst, G. G. J.: Ice in the 1994 Rabaul eruption cloud: implications for volcano hazard and atmospheric effects, Nature, 375, 477-479, doi:10.1038/375477a0, 1995

Sigurjonsson, H., Gisladottir, F., and Arnalds, O.: Measurement of aeolian processes on sandy surfaces in Iceland, RALA Rep. Agric. Res. Inst., Reykjavik, 201, 27, 1999.

Stamnes, K., Tsay, S.-C., Wiscombe, W., and Jayaweera, K.: Numerically stable algorithm for discrete-ordinate-method radiative transfer in multiple scattering and emitting layered media, Appl. Opt., 27, 2502-2509, 1988.

Stevenson, J. A., Millington, S. C., Beckett, F. M., Swindles, G. T., and Thordarson, T.: Big grains go far: understanding the discrepancy between tephrochronology and satellite infrared measurements of volcanic ash, Atmos. Meas. Tech., 8, 2069-2091, doi:10.5194/amt-8-2069-2015, 2015.
Thomson, D. and Wilson, J.: History of Lagrangian stochastic models for turbulent dispersion, in: Lagrangian modelling of the atmosphere, pp. 19-36, Geophysical Monograph Series 200, American Geophysical Union, Washington, 2013.

Thordarson, T. and Höskuldsson, Á.: Postglacial volcanism in Iceland, Jökull, 58 pp., 2008.

Thorsteinsson, T., Jóhannsson, T., Stohl, A., and Kristiansen, N. I.: High levels of particulate matter in Iceland due to direct ash emissions by the Eyjafjallajökull eruption and resuspension of deposited ash, J. Geophys. Res-Sol. Ea., 117, B00C05, doi:10.1029/2011JB008756, 2012.

Watson, I. M., Realmuto, V. J., Rose, W. I., Prata, A. J., Bluth, G. J. S., Gu, Y., Bader, C. E., and Yu, T.: Thermal infrared remote sensing of volcanic emissions using the moderate resolution imaging spectroradiometer, J. Volcanol. Geoth. Res., 135, 75-89, 2004.

Webster, H. and Thomson, D.: Dry deposition modelling in a Lagrangian dispersion model, Int. J. Environ. Pollut., 2011.

Webster, H. and Thomson, D.: The NAME wet deposition scheme, Forecasting Research Technical Report, 584 pp., 2014.

Webster, H., Thomson, D., Johnson, B., Heard, I., Turnbull, K., Marenco, F., Kristiansen, N., Dorsey, J., Minikin, A., Weinzierl, B., Schumann, U., Sparks, R., Loughlin, S., Hort, M., Leadbetter, S., Devenish, B., Manning, A., Witham, C., Haywood, J., and Golding, B.: Operational prediction of ash concentrations in the distal volcanic cloud from the 2010 Eyjafjallajökull eruption, J. Geophys. Res., 117, D00U08, doi:10.1029/2011JD016790, 2012.

Wen, S. and Rose, W. I.: Retrieval of sizes and total masses of particles in volcanic clouds using AVHRR bands 4 and 5, J. Geophys. Res., 99, 5421-5431, 1994.

Wilson, T. M., Cole, J. W., Stewart, C., Cronin, S. J., and Johnston, D. M.: Ash storms: impacts of wind-remobilised volcanic ash on rural communities and agriculture following the 1991 Hudson eruption, southern Patagonia, Chile, B. Volcanol., 73, 223-239, doi:10.1007/s00445-010-0396-1, 2011.

Woodhouse, M., Hogg, A., Phillips, J., and Sparks, R.: Interaction between volcanic plumes and wind during the 2010 Eyjafjallajökull eruption, Iceland, J. Geophys. Res-Sol. Ea., 118, 1-18, 2012.

Woodward, S.: Modeling the atmospheric life cycle and radiative impact of mineral dust in the Hadley Centre climate model, J. Geophys. Res.-Atmos., 106, 18155-18166, doi:10.1029/2000JD900795, 2001.

Yu, T., Rose, W. I., and Prata, A. J.: Atmospheric correction for satellite-based volcanic ash mapping and retrievals using "split window" IR data from GOES and AVHRR, J. Geophys. Res.-Atmos., 107, AAC 10-1-AAC 10-19, doi:10.1029/2001JD000706, 2002. 